Article

\title{
Stress and Adjustment During the COVID-19 Pandemic: A Qualitative Study on the Lived Experience of Older Adults
}

\author{
Alexandra J. Fiocco ${ }^{1,}$, , Charlie Gryspeerdt ${ }^{1}$ and Giselle Franco ${ }^{1}$ \\ 1 Ryerson University, Department of Psychology \\ * Correspondence: afiocco@ryerson.ca; Tel.: (416) 979-5000ext553008
}

\begin{abstract}
In response to the COVID-19 pandemic, social distancing measures were put into place to flatten the pandemic curve. It was projected older adults were at increased risk for poor psychological and health outcomes resulting from increased social isolation and loneliness. However, little research has supported this projection among community-dwelling older adults. While growing body of research has examined the impact of the COVID-19 pandemic on older adults, there is a paucity of qualitative research that captures the lived experience of community-dwelling older adults. The current study aimed to better understand the lived experience of community-dwelling older adults during the first six months of the pandemic. Semi-structured one on one interviews were conducting with independent living older adults aged 65 years and older. After achieving saturation, 22 interview were analyzed using inductive thematic analysis. Following a recursive process, two overarching themes emerged from the data: perceived threat and challenges of the pandemic and coping with the pandemic. Specifically, participants reflected on the threat of contracting the virus and challenges associated with living arrangement, social isolation, and financial insecurity. Participants shared their coping strategies to maintain health and wellbeing, including behavioral strategies, emotion-focused strategies, and social support. Overall, this research highlights resilience among older adults during the first six months of the pandemic.
\end{abstract}

Keywords: COVID-19; pandemic; stress; coping; older adults; resilience;

\section{Introduction}

On March 11, 2020, the World Health Organization declared the coronavirus disease (COVID-19) a pandemic. Institution closures and physical distancing measures were implemented to reduce spread of the SARS-CoV-2 virus and help flatten the pandemic curve. Amidst the pandemic, concern for the health and wellbeing of older adults has been a dominant focal point, with reports of increased risk for infection and death [1-3], and increasing risk of social isolation and loneliness [4] with the potential for a profound effect on the physical and mental health of older adults [5-7]. An initial collaborative report by The Irish Longitudinal Study on Aging (TILDA) and ALONE suggested a rise in social isolation and loneliness among older adults within the first four months of the COVID-19 pandemic [4]. Relatedly, in launching their support telephone helpline to continue serving older adults through their Support and Befriending Service, ALONE received over 26 thousand calls from older adults, 75\% of whom lived alone [4].

Despite increased risk for infection and concerns regarding social isolation, a growing body of literature suggests that, on average, older adults have fared relatively well during the pandemic [8-10]. In June 2020, the Centers for Disease Control and Prevention surveyed 5,412 Americans aged 18 year and older, revealing that adults 65+ years of age reported the lowest level of self-reported anxiety, depression, COVID-19 related trauma, substance use, and suicidal ideation [11]. Additionally, in a survey of 3,300 respondents in Quebec Canada, it was found that older adults 60+ years of age reported the lowest level of psychological distress and the highest perception of emotional wellbeing, compared to other age groups, between April and September of 2020 [12]. Finally, 
in a survey of 1,310 adults 18 to 88 years of age, increasing age was associated with lower perceived loneliness. However, negative self-perceptions of aging associated with greater perceived loneliness and psychological distress [13].

Experience of the COVID-19 pandemic among older adults is likely nuanced and modified by various factors, including perceptions of risk and personal resources. According to the Transactional Model of Stress [14] the experience of distress in any given context (e.g., COVID-19 pandemic) is determined by the relationship between a person and the environment that is perceived by the person as taxing or exceeding their resources and endangering their well-being. According to the model, a situation may be appraised as a threat or challenge, which interacts with the appraisal of resources to manage potential stressful internal-or external demands [14]. Consequently, the objective of the current qualitative study was to gain insight on the lived experience of older adults during the initial wave of the COVID-19 pandemic, to capture individual perceptions of the pandemic and resources used to manage its impact. Importantly, the value of qualitative analysis of personal accounts lies within it's potential to help better understand the ways in which older adults have managed the pandemic.

\section{Materials and Methods}

\subsection{Participants and Procedures}

Older adults were recruited from the community through online advertisements. Inclusion criteria entailed being 65 years of age or older, living independently in the community, having access to internet or a phone for the interview, and speaking English or French (i.e., the interviewer was bilingual). A total of 22 participants were recruited into the study before saturation was reached.

Interviews took place from May 18th 2020 to October 1st 2020. Following provision of verbal consent, participants engaged in a 30- to 60-minute telephone or virtual interview using Zoom. Before engaging in a semi-structured open-ended interview, participant answered close-ended questions pertaining to demographic characteristics and health status. The study was approved by Ryerson University's Research Ethics Board (\#2020-191)

\subsection{Measures}

Questionnaires included a demographic questionnaire to index age, sex, ethnicity, living arrangement, caregiver status, perceived socioeconomic status (SES), and religiosity. Participants were asked to list any existing medical and health conditions and to rate their health status on a 5 -point Likert scale ( $0=$ poor to $4=$ excellent). To assess the presence of depressive symptomatology over the last 2 weeks, participants completed the Patient Health Questionnaire-9 (PhQ9; [15]. Finally, participants were asked to rate their level of worry with respect to catching the SARS-CoV-2 virus on a scale from 1 (no worry) to 10 (high worry).

Semi-structured one-on-one interviews were audio recorded and transcribed verbatim. Open-ended questions asked participants to reflect on their experience with the pandemic and its impact of their daily life.

\subsection{Data analyses}

Descriptive analyses were conducted for quantitative data. Qualitative interviews were transcribed and analyzed by the authors using an iterative inductive thematic analysis such that the categories were generated from the data itself through open coding [16]. Following review of the transcripts, semantic and latent codes were generated to label recurring features of the data. Codes were clustered into themes and subthemes based on similarities and overlap in order to identify significant patterns in the data. The themes were then reviewed during a recursive process, and particularly salient extracts were selected. Following theme building, it was mutually agreed upon that theoretical saturation had been met. Transcripts were revisited to ensure that all relevant quotes had been extracted as well as to help further refine the synthesis of data. 


\section{Results}

\subsection{Participants}

Average age of the sample was 72.23 years $(\mathrm{SD}=4.25), 59 \%$ were female and $54 \%$ of the sample identified as being of European decent or Caucasian. A large proportion of the sample $(54.5 \%)$ identified as having a low-to-moderate socio-economic status. Approximately $68 \%$ of the sample reported having a medical condition; $23 \%$ reported that they were being treated for depression and/or an anxiety disorder; $23 \%$ reported presenting with a chronic pain condition; and 36\% reported being treated for hypertension. Additional ailments included thyroid disorder, hypercholesterolemia, diabetes, digestive problems, asthma, and glaucoma. Average score on the PHQ-9 was 4.27 ( $\mathrm{SD}=4.78)$. Overall, participants did not report a high level of worry with respect to catching the virus (mean score of 3.93, ranging from 1 to 6.5 on a 10-point scale). Please see Table 1 for participants characteristics.

Table 1. Participants Characteristics ( $\mathrm{N}=22)$

\begin{tabular}{|c|c|}
\hline Descriptive Variable & Mean (SD, range) or $n(\%)$ \\
\hline Age & $72(4.78, \min 65-\max 81)$ \\
\hline Sex (female) & $13(59)$ \\
\hline \multicolumn{2}{|l|}{ Ethnicity } \\
\hline Caucasian/European & $18(82)$ \\
\hline Black & $1(5)$ \\
\hline Asian & $2(9)$ \\
\hline Middle Eastern & $1(5)$ \\
\hline \multicolumn{2}{|l|}{ Relationship Status } \\
\hline Married & $13(59)$ \\
\hline Common Law & $1(4)$ \\
\hline Single & $6(27)$ \\
\hline Widow & $2(9)$ \\
\hline \multicolumn{2}{|l|}{ Relationship Status } \\
\hline Married & $13(59)$ \\
\hline Common Law & $1(4)$ \\
\hline Single & $6(27)$ \\
\hline Widow & $2(9)$ \\
\hline \multicolumn{2}{|l|}{ Living Arrangement } \\
\hline Alone & $6(27)$ \\
\hline Spouse & $12(55)$ \\
\hline Spouse \& Children & $2(9 \%$ \\
\hline Sibling & $2(9)$ \\
\hline \multicolumn{2}{|l|}{ Place of Residence } \\
\hline House/Townhouse & $10(45)$ \\
\hline \multicolumn{2}{|l|}{ Owned } \\
\hline Condo Owned & $7(32)$ \\
\hline Rental & $3(14)$ \\
\hline Group Housing & $2(9)$ \\
\hline \multicolumn{2}{|l|}{ Caregiver Status } \\
\hline Not Caregiver & $18(81)$ \\
\hline Primary Caregiver & $2(9)$ \\
\hline Secondary Caregiver & $2(9)$ \\
\hline \multicolumn{2}{|l|}{ Socioeconomic Status } \\
\hline Low & $1(5)$ \\
\hline Medium Low & $6(27)$ \\
\hline Medium & $7(32)$ \\
\hline Medium High & $6(27)$ \\
\hline
\end{tabular}


High

Prefer not to say

Religion

Christian

Buddhist

Jewish

Spiritual

Not religious

General Health Status

Poor

Fair

Good

Very good

Excellent

Existing Medical Conditions

No

Yes

PHQ-9 score

Worry for SARS-CoV-2 con-

traction

Note : $\mathrm{SD}=$ Standard deviation; $\mathrm{PHQ}=$ Patient Health Questionnaire
$1(5)$

$1(5)$

$6(27)$

$1(5)$

$7(32)$

$3(14)$

$1(5)$

$2(9)$

$7(32)$

8 (36)

$4(18)$

$15(68)$

$4.27(4.78,0-17)$

$3.93(1.52,1-6.5)$

\subsection{Lived Experience of the Covid-19 Pandemic: Qualitative Findings}

Two overarching themes emerged from the 22 transcribed interviews: 1 ) Threat and Challenges Associated with the Pandemic (Figure 1); and 2) Coping with the COVID-19 Pandemic (Figure 2). The first theme emerged from a range of perspectives on key experiences that were expressed as being a threat or a challenge stemming from the pandemic by some participants, but not others. The theme of threat and challenges gave rise to seven subthemes, including: threat of the virus, financial threat, media consumption and fear messaging, the challenge of living arrangement, physical distancing and minimal social interactions, health management and services, and the necessity of using new technology. The second theme exemplified how participants were managing, or coping with the pandemic, which translated into behavioral strategies, emotion-focused strategies, and social support. Selected quotes by theme and subtheme are presented in Table 2. All participant quotes are available in Supplement Table in Appendix A. 


\subsubsection{Theme 1: Threat and Challenges Associated with the Pandemic}

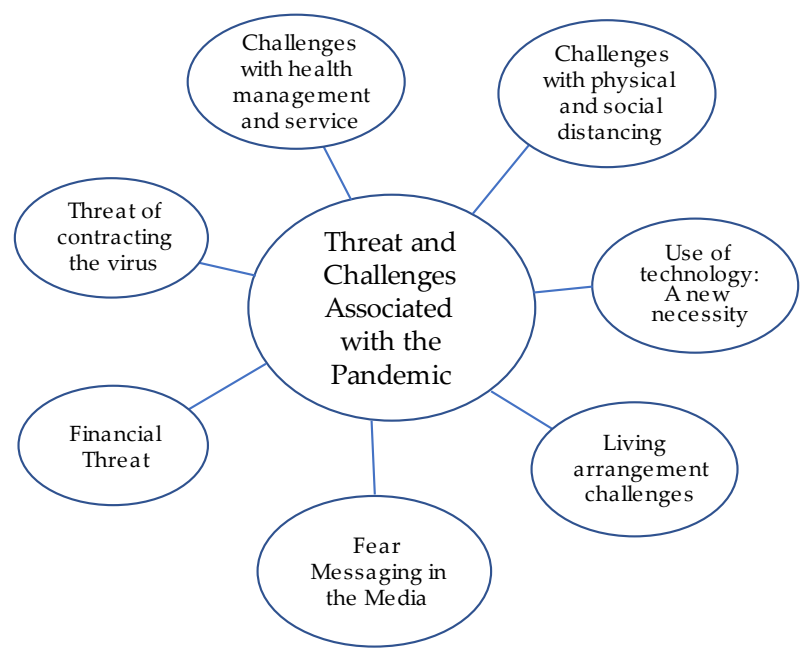

Figure 1. Theme 1 and Subthemes

\subsubsection{Subtheme 1: Threat of Contracting the SARS-CoV-2 Virus}

All participants reflected on perceptions of threat stemming from the COVID-19 pandemic. Overall, participants did not express extensive worry about personally contracting the coronavirus. Participants largely attributed this low level of worry to their good health and strong immune system, as well as their ability to follow "appropriate precautions". However, a few participants shared that they did experience infrequent worrisome thoughts, though nothing that significantly impacted their lives. One participant, in particular, who presented with an autoimmune disorder and depression felt that they were more vulnerable, especially since they would not be eligible for the vaccine.

Although participants were not generally worried about their personal risk of catching the virus, some participants shared concern of others' risk of catching SARS-CoV-2 virus, especially family members who were immune-deficient or living and working in high-risk environments (e.g., nursing home). Feelings of frustration and disappointment were expressed towards individuals who were not following the safety recommendations, especially younger generations who were described as selfish, irresponsible, and reckless. Some participants shared that their biggest fear was a continuation of the pandemic with no end in sight. Participants emphasized the need for a vaccine to bring the pandemic to an end, and dreaded subsequent waves and lockdowns.

\subsubsection{Subtheme 2: Financial Threat}

Financial concerns were shared by participants who were not retired. One widowed woman with a low socioeconomic status briefly shared her concern of affording her apartment without continued income; whereas another married woman feared that her husband's reduced income would eventually be challenging. However, participants who were retired felt that they were financially stable during the pandemic.

\subsubsection{Subtheme 3: Fear Messaging in the Media}

A majority of participants reported that the consistent negative and fear messaging presented in the media caused discomfort, and in some cases, anxiety. While consumption of media increased in the beginning of the pandemic, with some participants commenting on the addictive nature of the news, many participants recognized the media's negative impact on their wellbeing and chose to decrease their consumption. Many participants expressed that they felt discomfort due to chronic fear messaging on the news regarding 
the enhanced threat of the virus among older adults. Some participants expressed a mismatch between media messaging of supposed increased risk and their own personal health; many participants felt that the messaging was ageist and noted that they were healthier now, or just as healthy as when they were younger. Some participants also felt that the media overemphasized fear messaging and lacked in adequate pandemic-related education and health promotion for the public.

\subsubsection{Subtheme 4: Living Arrangement Challenges}

Living arrangement appeared to be an important factor that determined how well older adults were managing the pandemic. While living alone and living in small spaces presented with challenges, those living with others and living in a larger space benefited from their living arrangement. Participants who lived alone, especially those without existing family and "social bubbles", felt an increased sense of isolation and loneliness due to the inability to connect with others during the lockdown. With institutional closures, such as community centers and shopping malls, older adults who lived alone were stripped of their usual opportunities for social participation. One participant also shared concern with reduced tangible support, such as changing their smoke detector, due to restrictions associated with in-person visitations. In contrast, participants who lived with their spouse or family were less likely to express feelings of loneliness and isolation. Many expressed reliance on their spouse to serve as an emotional buffer and to help balance their mood. Participants living with others emphasized companionship and the importance of having someone else to take care of and spend time with, even if those interactions were of trivial nature.

For those living with others, the living space was an important factor that either positively or negatively impacted their pandemic experience. People living with others in a small space shared experiences of relationship strain due to a lack of personal space. Furthermore, some participants reflected on the difficulty of individual quarantine when living in a small space and the risk of spreading the virus within the household. In contrast, participants living with others in a larger space reflected on the utility of having different areas in the home to spend time away from their loved ones, when needed. Having their personal space allowed them to engage in their individual interests during the day, which was especially important for spouses with different interests. Those living in houses also shared how they were able to utilize their outdoor space, such as the front porch or back yard, to safely connect with others while maintaining social distancing.

\subsubsection{Subtheme 5: Physical Distancing and Minimal Social Interactions}

Regardless of living arrangement, a majority of participants reflected on changes in social engagement, many of whom lamented the loss of social connections due to recommended restrictions brought forth by the COVID-19 pandemic. The closure of gyms and community centers impacted participants' fitness regimes and daily group-based activities. Places of worship were closed, which removed an important community channel for many older adults. Some participants, especially those who self-identified as being "a hugger", reflected emotively on the challenge to be without physical contact from friends and loved ones. Some participants shared stories of their desperate attempts for physical contact such as simulating human contact by holding a body pillow.

Participants shared the experience of missing social gatherings with friends, lamenting the loss of social dinners, going to the movies, or going out for coffee with friends. One participant with post-traumatic stress disorder (PTSD) who lived with their sister disclosed that the inability to see their friends made it more challenging to manage their symptoms of anxiety. Still, a few participants who lived with their spouse shared that they were doing well with minimized social interactions.

Some participants reflected on missing their family, especially their young grandchildren. In some cases, the inability to connect with family was due to border closures and travel restrictions; in other cases, it was due to a mismatch of risk assessment and fear. More specifically, some older adults shared that they were not allowed to see their grandchildren because their children, or in-laws, assumed they were too fragile to be around the grandchildren. 
Some participants had experienced important life events during the pandemic, which were more difficult to endure due to social restrictions. A few participants reflected on the difficulty of physical distancing while mourning the loss of their loved one or feeling helpless while their loved one was in hospital without visitation options. One participant also shared their experience of retiring during the pandemic without a proper celebration to support the transition, resulting in a lack of closure.

\subsubsection{Subtheme 6: The Challenge of Health Management and Health Services}

In reflecting on personal health during the pandemic, a majority of participants expressed no major challenges or changes in their personal health. Few experienced transient sleep problems in the beginning of the pandemic due to initial worries about safety. However, some older adults with existing health concerns who rely heavily on health services expressed challenges with managing their health and navigating a changing healthcare system during the pandemic. Participants with pre-existing mental health concerns such as anxiety, depression, and PTSD largely attributed worsening of symptoms to a lack of control and social isolation. Furthermore, participants with pre-existing physical health ailments expressed various concerns, such as increased pain and muscle loss due to pandemic-related changes in their exercise regime.

Most participants were satisfied with the level of continued care for their medical conditions. One participant expressed a preference for the changes in their medical care, appreciating the ease of meeting with their doctors on a virtual platform. However, some older adults who relied heavily on healthcare services expressed concern and hesitations about the quality of virtual healthcare.

\subsubsection{Subtheme 7: Use of Technology: A New Necessity}

Given the restrictions on in-person interactions, a majority of participants expressed an increased reliance on and use of technology such as chat groups, Zoom, and Facetime. Many participants reflected on the learning curve associated with technology use and the additional supports needed when setting up Internet connections and online applications. Despite some of the initial resistance and challenges experienced by some participants, older adults recognized the new necessity of technology to remain connected with their social network during the pandemic and also noted unexpected benefits related to the ability to work, worship, and learn online. Still, almost all participants noted that social engagement via technology would never truly replace their need for human connection. Importantly, some participants acknowledged that learning how to use communication tools such as Zoom may be daunting for some older adults who believe that they are "too old to learn" and that the government should provide social assistance to support technology use within this segment of the population.

\subsubsection{Theme 2: Coping with the COVID-19 Pandemic}

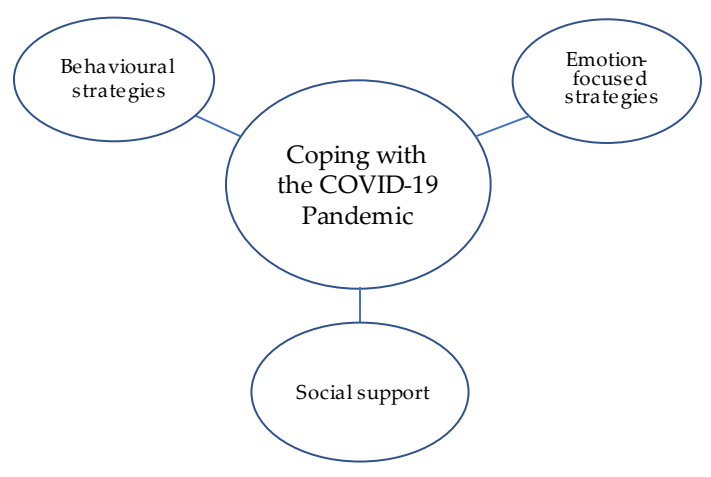

Figure 2. Theme 2 and Subthemes 


\subsubsection{Subtheme 1: Behavioral strategies}

To minimize the distress associated with media consumption, a number of participants shared that they pointedly reduced their consumption of the news. Those who wanted to stay informed reduced consumption to twice or once a day; one participant chose to peruse newspaper headlines as a way to stay informed, but not become overwhelmed.

A majority of the sample reflected on the responsibility of following COVID-19 health and safety regulations. Wearing a mask, hand washing, and physical distancing were seen as important behaviors to aid in curbing the spread of the coronavirus. Following the recommended practices was seen as an important civic responsibility, and contributed to a sense of personal safety. Persons with compromised immune function, or those living with an immune-compromised spouse, highlighted the importance of wearing a mask despite the discomfort. One participant with asthma and partial facial paralysis shared their experience of actively searching for a mask that was relatively comfortable, not only to protect their own wellbeing, but to protect others as well. This level of social consciousness was expressed by a number of participants in the sample. Despite experiencing discomfort with wearing a mask, one participant with asthma shared that wearing a mask sent a message of social responsibility to others in their community.

Behavioral strategies such as maintaining a daily schedule was an important coping strategy for many older adults. Participants also spoke to the importance of staying busy and finding new hobbies, such as gardening, baking, quilting, reading, and painting. Some participants shared the importance of pivoting, finding new opportunities to replace activities in which they were no longer able to engage. For example, one participant shared their ability to pivot from going to the gym, to creating a new art portfolio. Some participants viewed these activities as contributing their wellbeing while others simply saw it as a means of distraction. A few participants who did not have varied interests or hobbies before the pandemic seemed to experience greater challenge with the pandemic and finding purpose in their daily life. One participant without directive interests or hobbies likened the pandemic to ground hog day, with an overconsumption of television each day with their husband.

Keeping physical active was another common behavioral method of coping with the pandemic and maintaining wellness. Some older adults shared that their new "free time" allowed them to be more physically active than before the pandemic. In addition, simply being outdoors was perceived as an important strategy for maintaining wellness, especially for those living in smaller spaces.

\subsubsection{Subtheme 2: Emotion-focused strategies}

All participants shared the various emotion-focused strategies that were used to help manage living with the pandemic. Gratitude for small pleasures, acceptance of the current situation, and optimism for the future were commonly shared by older adults. Furthermore, perspective taking was notable in persons who had previously experienced hardship, trauma, or loss. For example, one participant who was a transplant patient noted that we have a choice to enjoy life, regardless of the current circumstances. Another participant shared that the pandemic was not as stressful as the hardship they experienced as a new immigrant to Canada. Taking a more general perspective, one participant reflected on what humanity has already suffered and survived, including war, the plague, and the great depression.

Meaning-making and positive re-appraisal were important strategies shared, allowing older adults to find the silver lining in their pandemic experience. Participants shared how the pandemic created new avenues for skill development, self-reflection and creativity, and how it allowed them to strengthen their relationship with family members. For some, the pandemic brought a sense of respect for the community as they watched people "step up to the plate" to adjust to new circumstance. Still, a few participants reflected on the need for greater social justice with respect to racism and the treatment of older adults 
living in residential care and nursing homes. One participant shared that their duties had become "more clear" as a anti-racism social activist.

\subsubsection{Subtheme 3: Social Support}

A majority of participants reflected on the importance of social support during the pandemic. Receiving support from family and friends, including both emotional and tangible support, was greatly valued by participants. As noted above, older adults living with their spouse or family were grateful for the consistent companionship during lockdown. One participant reflected on the support received by their children who lived oversees, which included special "care packages" with traditional Korean snacks and cards from the children and grandchildren.

Half of the sample reflected on their social 'bubble' and the valuable support from neighbors and friends. Some participants shared their attempts to maintain safe social gatherings with friends outside, on the porch in their back yard, or on their front lawn. Some participants commented on how neighbors have helped through porch drop offs, running errands, and through sharing items such as books. Further, participants detailed how friends have supported them through regular calls and virtual meetings. Some participants emphasized the importance of connecting with friends as a way of not feeling alone in "pandemic worry". Importantly, interviews also revealed that older adults living alone may necessitate a greater need and quantity of social support than is regularly available.

Participants not only reflected on how they were being supported, but also shared the importance of supporting others and the ways in which they were supporting friends, family and their communities during the pandemic. A few participants expressed how they have become more active in their communities by reaching out to others through regular phone calls, and the sense of purpose this has brought to their own lives. Yet, other participants reflected on the challenges of supporting others during the pandemic. For example, one participant expressed guilt over not being able to assist her essential worker colleagues during the pandemic and another participant expressed difficulties in supporting her mother in a nursing home.

Table 2. A Select Set of Participant Quotes by Theme and Subtheme

Theme 1: Threat and Challenges Associated with the Pandemic

codes

Subtheme 1:

Threat of Contracting the SARS-CoV-2 Virus

I'm really not that concerned if I catch it, I catch it, I'm hopeful that I would be able to pull through. I have a fairly good immune system when

Good health I get a cold. I do have asthma, and when I get a cold, it does flare it up, but I've always managed to control it so it's not severe enough that it really would worry me (\#14, 70 y/o Irish Jewish female, lives with spouse in condo)

I'm not worried about getting the virus. If I take appropriate precaution I

Taking precautions think it's practically zero ... it's unlikely that I'm going to get the virus unless someone I come in contact with has it and I break the rules $\# 12,70$ y/o Caucasian male, lives with spouse in a house)

Infrequent worry

"I try and take all the necessary precautions... but at the same time I do hear people get the COVID and they cannot figure out how they get it, so that can get me a little uneasy sometimes but it's not something I worry about, but in the back of my head I'm always saying well OK I'm doing 
Infrequent worry

Concern for others

Frustration with young adults

Fear for continues pandemic everything right and everything I'm supposed to do, I hope that's good enough for me not to get COVID" (\#18, 78 y/o Black female, lives alone in a house)

Because I have an autoimmune disease and I have a disability and stuff, I'm more vulnerable than if I was 25 years old. I have to be more cautious and you know make sure that I'm following the social isolating, and washing my hands a lot, wearing the masks because, with the illness that I have I'm never going to be able to have the vaccine, because I got my illness from having a vaccine from the flu shot, so I have to really protect myself from getting COVID (\#8, 71 y/o Caucasian female, lives with sister in co-op)

My daughter's job has been affected you know like 100\%. I mean it's amazing the changes she's had to go through and right from the very beginning, she is in a very vulnerable job which has been a worry you know, she's more exposed from frontline workers (\#13, 73 y/o Jewish male, lives with spouse in a condo)

From what I see everybody's following the rules, where it's the young people who don't seem to get it... They don't seem to take it as seriously. I've noticed other people's kids, in their 20s as well, jumping into cars with their friends and driving off, and I'm thinking 'oh my god' (\#22, 65 y/o Caucasian female, lives with spouse in a house).

I don't think anybody's gonna be safe, nobody is going to be safe, until we have an effective vaccine... they say that people will have to carry badges or in some way identify themselves as having been vaccinated before we can relax any of these face masks or social distancing but I think that will be the only true end of this is that when we have an effective vaccine (\#13, 73 y/o Jewish male, lives with spouse in a condo)

Subtheme 2:

Financial Threat

My biggest concern is probably financial because I worry that my husband still works as a [occupation] and he needs to go to see clients and the clients aren't as busy. I am 70, they wouldn't employ me any longer and it's not, I mean, I worked as a [profession], I haven't lost that ability, but they just don't see it... in that sense, that bit upsets me and so I have to rely on my husband's income and on our pensions, and that it's tough. It's tough to live in a fixed income these days (\#14, $70 \mathrm{y} / \mathrm{o}$, Irish Jewish female, lives with spouse in condo)

My biggest concern ... that financially I can stay in my apartment, and I can afford it.(\#2, 74 y/o Caucasian female, widow lives alone in condo) Subtheme 3:

Fear Messaging in the Media

I as a CNN junkie. I'm now not doing that because I don't think that's healthy either... I know fear of catching the virus is fueled by media coverage because now that I don't listen to it, like very little, I'm much happier. Yeah. I think at first it was just like it was like an addiction (\#5, 74 y/o Caucasian female, lives with spouse in a house)

Every time I watched the news I would just feel my heart sink a bit ... I wanted to stay informed as best I could, but I found that it just got to be too much so I limited it to twice a day probably (\#6, 71 y/o Caucasian female, lives alone in a house)

When it all first came out... a lot of what we heard was that it was going to affect 'us' more than anyone else, and that played on my brain a little 
Ageist fear messaging

Ageist fear messaging

Media lacking

codes

Living alone

Living alone

Living with spouse

Living in small space

Living in small spaces

Living in large spaces bit... all you heard was 'be careful of the', you know, 'it's the seniors' (\#5, 74 y/o Caucasian female, lives with spouse in house)

All we heard was it definitely is going to impact people over the age of 65 or 70, and stay home. Basically, we don't have enough ventilators for you folks - you need to flatten the curve because you're the ones that are really going to put a stress on the system. I had a social obligation. Like, even if I did poke my head out the door it's like 'Oh my gosh people are going to know I'm over 65' and they're going to probably look down on me because I'm not in my house. So, for a while I was afraid to go out for a walk even (\#6, 71 y/o Caucasian female, lives alone in a house)

Everybody says that if you're 60 or older you are more in danger. I don't believe in living my life in fear. I mean, I know that I'm 70, but in reality most of the time, other than with my arthritis, I don't feel any different than I did when I was bringing my kids up... And my age doesn't, as far as I'm concerned... it's only a number (\#14, 70 y/o, Irish Jewish female, lives with spouse in condo)

I find that the news is not really giving us good information...we are finding that the information is not very clear at all, even with government websites, certainly not in the newspapers (\#13, 73 y/o Jewish male, lives with spouse in a condo)

\section{Subtheme 4:}

Living Arrangement Challenges

One of my ways of getting some sort of social interaction would be to go grocery shopping. I would go pretty well every day because I needed to. That's the way I shopped, and so of course when everything was in lockdown, I couldn't do that and what I found was a greater sense of isolation (\#15, 65 y/o Ukrainian female, lives alone in a house)

Even if something small broke down like my smoke detector.. it started beeping and I couldn't get anybody to come in to take the stupid thing down and put in a new one because no one was coming into the house and that was true for anything really, anything that you needed done. It's very much that feeling of helplessness (\#15, 65 y/o Ukrainian female, lives alone in a house).

People in our condo who are widowers, and some of them have trouble coping with being alone. So even though we're not together all the time in the condo, we're in our separate rooms at times, you know that person is there, and you can discuss what you like about what they're showing on House Hunters or things like that, or have a friendly competition of answering the Jeopardy questions or Wheel of Fortune (\#11, July 14th, 74 y/o Jewish male, lives with spouse in condo).

We're more cross with each other and I think that's just inevitable. we're together 24 hours a day, most of the time, and that's too much for anybody (\#7, 81 y/o Caucasian male, lives with same-sex spouse in an apartment)

If you catch the virus, you need to quarantine yourself. But because of the construction of our townhouse. If one of us catches it, well then the person has to quarantine. But what about the other two? They might be in danger of catching the virus (\#1, 75 y/o Filipino male, lives with spouse and children in a house)

"We've got a big backyard, we're back on a ravine, so we've got privacy back there, we can go sit back there. We tend to sit out front, decked out front as well because the neighbors walk by and you talk to people. And 
its big enough so that we can have someone on the deck and still be social distanced by 6 feet. Which we do" (\#22, 65 y/o Caucasian female, lives with spouse in a house).

codes

Missing outings

Missing social groups

Missing social groups

Missing places of worship

Missing grandchildren

Need for human contact

Need for emotional wellness

Life event

\section{Subtheme 5:}

The Challenge of Physical Distancing and Minimal Social Interactions

Gone are the days sitting around eating a meal, going to the movies, all that stuff. I mean, normally we would like to get together, go for a walk, or a swim, and then go eat or have a coffee, and we would walk in the valley or somewhere nice. That's gone (\#20,67 y/o Caucasian female, lives with spouse in condo).

"All my social interactions like my group that I'm involved with and volunteering at the hospital is all cancelled so that was kind of hard because you don't have any social outlets that way" (\#2, July 2nd, 74 YO Caucasian female, widow lives alone in a condo)

My social sphere is restricted dramatically... my life isn't noticeably worse because I don't get to spend a couple afternoons at the senior center. Now for some people though, that's their whole world, and they're there every day all day long (\#12, 70 y/o Caucasian male, lives with spouse in a house).

Before the pandemic, I was in the synagogue twice a day and, you know, communing with a group of people... but some of it has had to be completely cancelled and I will say I have adapted, but it's still a big change in my circumstances (\#13, 73 y/o Jewish male, lives with spouse in condo).

We cannot see our grandchildren up close and personal because, well because they [the parents] don't want us, they don't want to risk our being with the kids..." (\#7,81 y/o Caucasian male, lives with same-sex spouse in an apartment)

Now, I'm a hugger. It's painfully hard for me to not run up and throw myself all over someone. I can do the elbow thing now. I'm learning. This is a day-by-day thing I will not lie. I'm not ashamed to say this. I have gone in the bedroom after the bed is all made later in the day and that [body] pillow is there and I have actually laid down and I've hugged it and I'm not ashamed to say that. And there is a little bit of comfort and, you know what, you take what you can get. Sounds ridiculous, but whatever works. Everybody should have a pillow (\#5, 74 y/o Caucasian female, lives with spouse in house).

Not being able to see my friends has made it harder for managing my post-traumatic stress... I have to be very careful about what I read and what I watch on movies or TV or whatever, that it doesn't trigger me so being in COVID and not being able to see some of the people that I miss has made it a little harder $(\# 8,71$ y/o Caucasian female, lives with sister in co-op).

Well, I live on my own now, which is a big change. So that's an adjustment for me because cooking for one... and what I do is I put the radio on as soon as I wake up, and that helps because somebody is talking, you know? I'm so happy for my radio. [My husband] didn't die of COVID-19 it was just his heart gave out, you know? In the hospital, I could not visit because of the COVID and so his decision was to have palliative care, which in a way was really good because he was with me, you know? ... I make sure I have a distance which is kinda sad in a way, but that's the way it is right, can't be hugging anybody... I find that very hard 
especially after a loss you know (\#2, 74 y/o Caucasian female, lives alone in condo)

And during that week I was supposed to have a retirement party - three of them scheduled for the last week. And so when I went home, every-

Life event thing was cancelled. I didn't get to say goodbye to my friends. Some of them probably didn't even know I was retired. Everything just went poof and it was gone (\#1, 75 y/o Filipino male, lives with spouse and children in house).

codes Subtheme 6:

The Challenge of Health Management and Health Services I am a member of the [community center] and that was my outlet for exercise [for my scoliosis]. I went to three-to-five classes for aquafit and I

Maintaining health routine

Health services

Health services

Health services

codes

New for new learning

Need for new learning swam approximately a mile a week - that's gone. So I've been more than half a year without this wonderful exercise that made me feel a lot more energetic than I am now" (\#7, 81 y/o Caucasian male, lives with same-sex spouse in an apartment).

You still get the intrusive thoughts but you don't have to act on them. But

Exacerbation of existing symptoms (OCD) I noticed it has been exacerbated during this pandemic (\#20, 67 y/o Caucasian female, lives with spouse in a condo).

My family doctor and I have had that chat on whatever system I don't know whether it was Zoom or not, but some sort of system. I'm supposed to have a checkup once a year, we did that over the Internet. I'm on a clinical trial with $\left[{ }^{*}\right.$ hospital name* ${ }^{*}$, we did that over the Internet. My whoever he is for my colitis, we've done that over the Internet. I mean sometimes I wonder why I go see all these people! (\#9, 73 y/o Caucasian male, lives with spouse in house, liver transplant patient, ulcerative colitis, primary sclerosing cholangitis)

I used to go just over half a block away and go see my doctor and get appointments within the week and now you have to go through all these gatekeepers, you have to go through somebody on the phone that doesn't know you, and then I talked to the nurse who does know me and then she talked to the doctor and, you know, so it's levels and levels of bureaucracy to get to your doctor (\#10, 72 y/o Celtic Jewish female, lives with sister in co-op housing).

I've had a Zoom doctor appointment and I'm concerned a little bit about how they've managed anything if they physically needed to see me... I think we've had some diminishment in medical attention, obviously they've been focusing on people who are much sicker (\#13, 73 y/o Jewish male, lives with spouse in condo)

\section{Subtheme 7:}

Use of Technology: A New Necessity

I've had to bunk up on my technology, I've had to learn how to do zoom, I've had to learn how to photograph a check and not go the bank... So, we're adapting to more of an online presence in our life, for everything banking, talking to people, zooms. I'm more terrified of going out in public than I am of technology (\#22, 65 y/o Caucasian female, lives with spouse in a house).

"It was a learning experience. I don't really one hundred percent like it as much. Like playing bridge online, or doing book club online, you know what I mean, it's not as nice as being in a group setting that you have each other, you know. It's okay... but I wouldn't like it to have it all the 
time like that. I don't want it to stay forever that way... In the meantime, I adjust (\#2, 74 y/o Caucasian female, widow lives alone in a condo). Some older adults don't have the means to really communicate. For example, they don't have computer skills, Zooming, and so on... Some need help, encourage them to be more active... help them find the means of communicating with others. There was one person but then she was adamant she didn't want to use the Zoom. She thought it's so complicated and she didn't have a camera, she didn't have a microphone. I really tried to push her and finally she is now happy that she is doing it, so there are

Need for assistance people to help. I think for older people it's not only the medical and physiological assistance, they need some social assistance. Like you know providing them with all the new means of communication, computers, somebody goes and shows them how to use the Zoom, installs cameras, and so on. These people don't have the skill and some of them really not forthcoming they are not... because they think they are too old to learn these new techniques (\#17, 77 y/o Middle Eastern male, lives with spouse in a condo)

We both have our own laptop, so we can reading, listening, musical arts performance is more than before. Free, hahahah! Specially opera, which I

Unexpected benefits am really fanatic about, and he likes the sports, so we have own time to do that without much boredom or anything (\#19, 78 y/o Korean female, lives with spouse in a condo).

Theme 2: Coping with the COVID-19 Pandemic

codes

Mask wearing

Making a schedule

Pivoting

Keeping busy

Importance of being self-directed
Subtheme 1:

Behavioral strategies

Because I'm asthmatic, I was wearing the disposable masks, I really had trouble breathing. But I was determined to find a mask I could wear, and since then, we've found cloth masks that don't bother my breathing so much. I tried to find something that would work instead of just saying 'well I can't wear a mask,' because I feel very vulnerable with my autoimmune disease. I'm glad that I found that because I feel protected and I'm protecting other people from me too because, my mouth is paralyzed and a lot of times spit will come out of my mouth unintentionally, so I'm protecting other people when I'm out too... I have a good social conscience, I don't want to make anybody else sick and I don't want to get sick (\#8, 71 y/o Caucasian female, lives with sister in co-op)

I try to make sure I have a schedule. I get up, I do a fitness routine, I get dressed, I have a zoom something in the morning or, you know I really try hard to make sure that I do have the structure. And I also make sure that I get out every day because I think, first, the fresh air, and also I'm very lucky, I live near a ravine, so I see lots of green, which is very important for me (\#21, 75 y/o Jewish female, widow lives alone in a condo). It didn't really impact my wellbeing at all, it was just a shift in what to do with my available free time. Instead of sitting around and moping, you know, I walked more, biked more, made it home more, watched the news. It's just a shift in how one occupies oneself, productively, stimulating (\#16, 70 y/o Jewish male, lives with common law partner in a condo). Gardening, I think, takes my mind off a lot of other things, cuts about the weed. I think that's all healthy stuff... I think our busyness helps (\#5, 74 y/o Caucasian female, lives with spouse in a house)

Well because it's like you have no purpose, like you can't go do the things you normally would do, you know, like you know, on a Monday I did 
Physical activity

Being outdoors

this, I went here and I... all that stuff I can't do. I can't socialize with a group of friends and go play cards or do whatever because we can't do it right now, you know, so anything you planned or look forward to, you really can't do, you know ( $\# 4,69$ y/o Caucasian female, lives with immune compromised spouse in house)

We do most of our walking in the morning, if it's a nice day and by that I mean 24-25 degrees, we'll walk in the afternoon sometimes, and I'll be honest our deck overlooks a walking path and we see a lot of seniors walking. They walk and they walk and it's a way to break up the monotony of being indoors ( $\# 9,73$ y/o Caucasian male, lives with spouse in a house).

The garden has been a tremendous comfort to counteract all that other negative stuff ( $\# 7,81$ y/o Caucasian male, lives with same-sex spouse in an apartment).

Subtheme 2:

codes

Emotion-focused strategies

You have to kind of believe that it's going to be OK because I think if you're a negative person and you just go to bed at night and go you

Hope know it's all for naught. Well, that's tough. I think that's a hard way to live, and I think that's going to make people ill (\#5, 74 y/o Caucasian female lives with spouse in a house)

I think the more you open your mind to what you could be doing, the pandemic takes a little back seat for that while... We're both ice cream people, so we just go get an ice cream and sit in the car and eat it and

Gratitude and small pleasures

Perspective taking

Perspective taking

Meaning making

Silver lining come home, you know. I think you have to pick your pleasures. They're little, but they're not as little as they used to be. Now getting an ice cream cone is a big deal (\#5, 74 y/o Caucasian female, lives with spouse in a house)

Transplant patients have learned to look after themselves... and so I don't know! I guess I'm so grateful to be alive that I'm going to enjoy every minute of it. The gratitude that I have today is much greater than I ever had before.... possibly the experience that I've gone through, I've had a second chance at life, like I should be dead, right?... and so you have a choice, you can either bounce off the walls or you can enjoy what you got! Yeah we're living through a tough time right now, you have a choice to enjoy it or not, I choose to enjoy it (\#9, 73 y/o Caucasian male, lives with spouse in a house)

We came here at a vibrant age. Immigrant here. So we face difficulty in mid-20s. So maybe not like pandemic COVID-19 hardship, we had already hardship without the language, plus some level of racism and then during that time I was pregnant ( $\# 19$, 78 y/o Korean female, lives with spouse in a condo)

There is a COVID-19 pandemic versus a racism pandemic. But this COVID-19 pandemic gave me more voices about the decision... I have more facts to [relay] to other people in my community who are kind of ignorant with subtle racism underneath. So, we need more education about it. Its all relatable. Its nothing separate issues (\#19, 78 y/o Korean female, lives with spouse in a condo).

People have stepped up to the plate to try to adjust to new circumstances and they've done remarkably well in my opinion...this challenge [the pandemic] has really made us see what wonderful people that we have in our community (\#13, 73 y/o Jewish male, lives with spouse in a condo). 
codes

Being connected

Sharing

Supported by spouse

Need for more support

Supporting others

Difficult to support others at times
Subtheme 3:

Social Support

So, part of the ease of going through the pandemic is the way we're all connected. Fifty years ago, how would you have done? (\#12, 70 y/o Caucasian male, lives with spouse in a house)

It's just maybe three women sharing three different feelings, and most of those conversations end up in all three or all four of us being a whole lot better because, you know, you're not the only one feeling it. You know, you're not the only one that doesn't have the answers, and that gets scared sometimes. But I find my outlet with my friends always makes me stronger and I think we all we all hang up and go, 'Yeah I can do this. I feel better' (\#5, 74 y/o Caucasian female, lives with spouse in house) He's definitely the one that will talk me down from something. So, if I say, you know, “What if?" He'll just say, “Don't what if it.” Just, you know, we'll cross that bridge. He's a lot more sensible and not up and down like I am (\#5, 74 y/o Caucasian female, lives with spouse in house).

I am always wishing for more support and I, so that's you know, that's an ongoing theme for me...my hopes and my wishes for you know social interaction and for people, you know coming to take care of me is unrealistic, and it was unrealistic before the pandemic. It's great that my brother would come every Saturday but I also wanted him to phone me twice a week. Or even my friend in [city], I would hope that she would call me more than once a week ... I think people have their own lives, I don't think that's completely realistic but that's what I would want (\#15, $65 \mathrm{y} / \mathrm{o}$ Ukrainian female, lives alone in a house).

Father Vincent [pseudonym] sends me little jobs... my capabilities on the Internet are limited and he knows that so he'll give me a list of calls to parishioners and just say 'I'm calling on behalf of Father Vincent who just wanted to know how are you doing? Do you need anything?' You know, so that's a blessing. 'Cause if you call 5 people in a day and you help one person who's alone and say to them, 'Listen, I'm calling on behalf of the perish, but you can have my phone number, and if you just wanted to chat you know I'm home, I'm stuck here too'. I've had a few calls, and I have to tell you, if you ever think that that's not a blessing, you're crazy, because that will take your mind off anything that you're feeling. A couple of times, I talked to a senior, and I don't know if I made them feel better, but I felt better. It was like I was talking to me (\#5, 74 y/o Caucasian female, lives with spouse in a house)

I would just take a little chair, sit outside her window when they open up the top so we could hear each other talk you know, stuff like that. ... like not being able to go in and explain to her, that's been my biggest... breaks my heart! because she doesn't understand... and then she'll say like there's nobody here, nobody comes, and stuff like that, 'cause they're all confined to their rooms so they don't leave the room at all... and she hasn't left it in three or four months so that's hard (\#4,69 y/o Caucasian female, lives with immune compromised spouse in a house)

\section{Discussion}

Within the first few months of the pandemic, communities across the world faced a momentous disruption to their livelihood. Although initial reports suggested that older adults were at increased risk of psychological distress stemming from social isolation 
and loneliness (Ward et al., 2020), emerging evidence suggests that older adults have displayed greater emotional resilience during this pandemic, relative to younger age groups $[4,12]$. The present study provides a qualitative perspective of the lived experience of community-dwelling older adults within the first six months of the COVID-19 pandemic. Most notably, the current qualitative results support existing quantitative findings of resilience among older adults during the pandemic.

Despite targeted fear messaging on the news and social media, suggesting an increased risk of viral contraction among older adults, participants did not express heightened concern regarding their personal risk of catching the virus due to their age. However, the news media portrayal of COVID-19 as an age-related disease created anxiety in some participants. While media consumption initially increased among many older adults in order to remain informed of the evolving coronavirus and the recommended safety practices, participants also noticed the negative impact that media consumption was having on their emotional wellbeing. Recognizing the need to regulate media consumption, those who chose to decrease their media intake shared that they experienced an improvement in their psychological wellbeing. These findings are aligned with previous research pertaining to COVID-19 media consumption. In a study by Losada-Baltar et al., [17] greater time devoted to COVID-19 information was associated with greater psychological distress during lockdown. Furthermore, data from the American Trends Panel, which sampled adults aged 18 years and older, revealed that greater COVID-19 media consumption was associated with greater psychological distress, which was partially explained by increased perceptions of COVID-19 threat [18]. Together, results highlight the importance of recommending guidelines surrounding media consumption. More specifically, qualitative findings underscore the importance of being an active participant in media consumption, which includes bringing awareness to how specific media are influencing personal wellbeing, and the ability to disengage from counterproductive behaviors.

General low concern for contracting the SARS-CoV-2 virus among participants was commonly attributed to a sense of one's personal health or to the engagement in prescribed cautionary behaviors. Those with a compromised immune system felt confident in the prescribed safety measures, emphasizing the importance of physical distancing, hand washing, and the wearing of masks. Due to the prevalence of contentious discourse around mask wearing, many participants conveyed their strong belief in the importance of wearing a mask, not just for personal safety, but for the safety of others. Indeed, greater concern for others' wellbeing was emphasized among older adults, which is aligned with the notion that aging is associated with greater altruism [19]. Considering that altruistic attitudes predict positive affect in later adulthood [20], caring for the personal safety of others and engaging in prosocial behaviors (discussed below) during the pandemic may reflect a characteristic of resiliency among older adults.

Due to institution closures, participants who were still employed expressed financial concern with continued lockdown. Those who were retired commonly expressed gratitude for being in retirement and financially secure. Many older adults acknowledged that the common pandemic stressors experience by Canadians, including loss of employment, financial insecurity, and homeschooling young children, was not a concern for older adults, which may partially account for quantitative findings of increased perceptions of stress among younger adults relative to older adults [12].

Participants shared the challenges associated with social distancing measures and institution closures. Within the current sample, stories were very similar with respect to loss of social connection and daily routine due to the closure of community centers, gyms, and places of worship. Stories of loss and bereavement during times of social confinement highlighted the importance of social connectedness during important life transitions - a testament to the value of community and family support. Overall, participants expressed a sense of being supported during the pandemic. Participants living with a spouse expressed gratitude for having someone to spend time with; however, living space emerged as an important factor for managing the pandemic day to day, with 
larger spaces affording the benefit of having moments of solitude. Research to date has largely focused on the effect of the pandemic on indices of loneliness, without considering the need for solitude. Although the need for solitude may differ by age, personality, and circumstance, solitude has been found to support the freedom to engage in personal interests and to foster creativity and spirituality [21].

Many older adults shared a deep sense of community with their neighbors, reflecting on times spent socializing at a distance, helping one another with running errands, or sharing resources. Further, engaging in social outreach activities in their communities provided older adults with a sense of purpose during the pandemic. Sense of purpose in later adulthood has been shown to support healthy lifestyle behaviors [22] and is a cornerstone of wellness in late life [23]. Altogether, stories of personal lived experiences underscore the importance of social capital, including neighborhood cohesion and norms of reciprocity, which may facilitate a sense of purpose and minimize the potential isolating effect of the pandemic. Indeed, engagement in prosocial behaviors as means of communal coping may also foster wellness within the community [24].

While worry of contracting the virus was minimal within the sample, some participants with existing psychological health ailments (e.g., obsessive compulsive disorder, post-traumatic stress disorder, depression) expressed that their symptoms were initially exacerbated by the pandemic. Accordingly, ensuring that proper health support systems for persons with existing health ailments is essential. However, none of the participants shared onset of new psychological or physical diagnoses resulting from the pandemic, which is aligned with the aforementioned quantitative report by Dionne et al., [12]. Rather, participants shared various strategies employed that helped them manage day to day pandemic living, an indication of resilience and ingenuity. With regards to access to healthcare, a notable portion of the sample discussed their experience adapting to changes in access to medical services, and their relief at being in good enough health to afford to adapt to delays in visits to optometrists and dental professionals. Of note, one participant who lived alone and was particularly reliant on their family doctor was very disappointed with the closure of their clinic, which was located in a lower income neighborhood.

A myriad of coping strategies recounted across interviews highlights the importance of behavioral and emotional coping strategies to mitigate the potential negative impact of pandemic stress on wellbeing. Behavioral strategies were important for the management of institution closures. A majority of older adults, including those with mobility issues, spoke about keeping physically active during the pandemic. Such behavior is supported by a large body of research that highlights the importance of physical activity for physical and emotional wellbeing among older adults, including resistance to negative aging stereotypes $[25,26]$. As noted above, a number of participants expressed low worry about contracting the virus, which was frequently attributed to their sense of good physical health and hardiness. Accordingly, the ability to remain physically active during the pandemic may support a sense of physical and emotional wellness, even among persons with existing health ailments.

While the ability to pivot daily activities was shared by a majority of the sample, one participant shared difficulty finding new ways to shift their activities of daily living. They found that they had "no purpose" and were unable to draw on existing interests or hobbies. According to self-determination theory, the ability to engage in internalized goal directed behaviors is largely dependent on need for autonomy, competence, and relatedness [27]. Consequently, persons who lack a sense of autonomy and choice during the pandemic may find it more difficult to rely on internal motivations and to pivot their daily activities to support their wellbeing. This may be especially salient for individuals who rely on external sources of pleasure and gratification [27].

A range of adaptive emotion-focused coping strategies were shared across interviews, all of which support wellbeing. A prominent emotion-focused strategy was perspective taking which afforded a sense of strength in overcoming adversity. Examples of gratitude, meaning making and positive reappraisal were commonly noted in the 
qualitative analysis, all of which are interconnected and foster positive emotions. According to Fredrickson's broaden-and-build model, the cultivation of positive emotions such as gratitude is a cognitive-emotional process that broadens the individual's thought-action repertoires, which over time fosters the building of emotional, social, and physical resources, which in turn enhance wellbeing [28]. Finally, participants expressed the ability to let go of the desire to change what was outside of their reach, focusing instead on the smaller changes and adaptations that they had the power to make within their daily lives. Shifting focus away from what is outside of one's control toward that which is controllable is importance for wellbeing as it fosters healthy lifestyle behaviors, psychological wellbeing, and physical health [29].

Silver linings around the pandemic were shared by many, including the need and benefits of to learning a new tool, namely Zoom. Although resistance to the use of new technology varied, many were grateful that they had a new means of communicating with loved ones and a way to continue engaging in social and learning activities. Previous research suggests that internet use among older adults supports wellbeing and is associated with reduced loneliness and greater life satisfaction and psychological wellbeing [30]. However, resistance to learning new technology was present among some older adults due to novelty and the lack of confidence to use new technology. The stories shared by older adults point to the importance of telecommunications support for older adults, including accessibility and skill development. While characteristics of aging cohorts continue to change, it is important to address aging stereotypes within the community, including the well know "I'm too old to learn" stereotype, which hinders healthy aging [31,32]. Continuing education and social programming is essential to breaking down barriers that are created by aging stereotypes, and to foster skill development in later adulthood.

Despite the important contribution of this report to the growing body of literature, it is important to reflect on study limitations. First, although saturation was met following interviews with 22 participants, all participants resided in the province of Ontario, Canada. While participants lived in both urban and rural environments, the experience of older adults in Ontario may not be representative of other geographical locations. Second, although the authors intentionally worked towards recruiting an ethnically diverse sample, a majority of the sample was Caucasian, with a select few who identified as being part of a minority group. As social determinants influence health and wellbeing [33], it is important to consider how the overrepresentation of some ethnic groups in essential workplaces, as well as financial insecurity and multigenerational living may differentially impact the experiences of older adults during the pandemic. However, given the qualitative nature of the study design, this analysis does not attempt to generalize findings to the greater population. The value of qualitative analysis is in the ability to provide a descriptive snapshot of the experience of a given sample. A final limitation pertains to timeline of the interviews, all of which were conducted during the spring and summer months of 2020. It is unclear whether the activities and coping strategies employed during these months continued into the winter months and during the extended pandemic.

\section{Conclusions}

Overall, the lived experiences shared by older adults in the current study are largely reflective of recent quantitative studies suggesting that older adults have been relatively resilient during this pandemic. They did not feel that they were at increased risks of contracting COVID-19; they did not report the onset of new health-related concerns within the first six months of the pandemic; and they did not feel a need to be treated differently due to their age. What has surfaced during the pandemic is a need to break down age-related stereotypes that compromise the livelihood and wellbeing of aging Canadians; the need to engage in careful reflection on media intake and its impact on emotional wellbeing; the need to develop and foster prosocial behaviors and communal coping to support wellness within the community; the need to establish accessible 
health support systems for persons with existing mental health ailments; and the need to create social programing that increases access to telecommunications at any age.

Supplementary Materials: The following are available online at www.mdpi.com/xxx/s1, Figure S1: title, Table S1: title, Video S1: title.

Author Contributions: Conceptualization, A.J.F.; methodology, A.J.F.; formal analysis, A.J.F., C.G., G.F., X.X.; data curation and transcription, C.G., G.F.; writing-original draft preparation, A.J.F.; writing-review and editing, C.G., G.F. All authors have read and agreed to the published version of the manuscript."

Funding: "This research received no external funding"

Institutional Review Board Statement: “The study was conducted according to the guidelines of the Declaration of Helsinki, and approved by the Ryerson University Research Ethics Board (\#2020191).

Informed Consent Statement: "Informed consent was obtained from all subjects involved in the study."

Data Availability Statement: All relevant de-identified quotations are provided within the study manuscript and supplemental data

Conflicts of Interest: "The authors declare no conflict of interest."

\section{Appendix A. Supplement Table with Study Quotes}

\section{Theme 1: Threat and Challenges Associated with the Pandemic}

codes

Good health

\section{Subtheme 1:}

Threat of Contracting the SARS-CoV-2 Virus

I'm really not that concerned if I catch it, I catch it, I'm hopeful that I would be able to pull through. I have a fairly good immune system when I get a cold. I do have asthma, and when I get a cold, it does flare it up, but I've always managed to control it so it's not severe enough that it really would worry me (\#14, 70 y/o Irish Jewish female, lives with spouse in condo)

Compared to others of my age, I feel that I will not be affected by the virus. I wont get it. Accidentally we might catch the virus through no fault of our own... If one of us catches it, well then the person has to quarantine. But what about the other two? They might be in danger of catching the virus. (\#1, 75 y/o male, Filipino, lives with spouse and children in townhouse)

I always thought of myself as a fairly healthy person, and I was really grateful for it, to kind of know that my immune system was in a really good place. (\#6, 71 y/o Caucasian female, lives alone in house)

I look at it from a point of view like I'm 73 years old and if I get it, I may not survive it, I don't know, but I don't feel old and I don't feel unhealthy in any way. (\#9, 73 y/o Caucasian male, living with spouse in house) I'm really not that concerned if I catch it, I catch it, I'm hopeful that I would be able to pull through. I have a fairly good immune system when I get a cold. I do have asthma, and when I get a cold it does flare it up, but I've always managed to control it so it's not severe enough that it really would worry me (\#14, 70 y/o Irish Jewish female, lives with spouse in condo) 
Taking precautions

Infrequent worry
I'm very calm nature in my mental health situation. Both of us [referring to husband]. So nothing panic about it. It depends on how you deal with it. We both believe in that. We have control. Not other." (\#19, 78 y/o Korean female, lives with spouse in a condo)

Well even though technically I'm a diabetic, because I'm now exercising much more frequently, I'm now feeling fitter than I have ever done for 20 years. You know, I'm feeling fitter than I was in the mid 50s, so it's just remarkable... even though technically I should be at risk, but the reality is that I'm feeling quite fit. (\#13, 73 y/o Jewish male, lives with spouse in a condo).

I'm not worried about getting the virus. If I take appropriate precaution I think it's practically zero ... it's unlikely that I'm going to get the virus unless someone I come in contact with has it and I break the rules (\#12, 70 y/o Caucasian male, lives with spouse in a house)

Very slightly worry about pandemic because I am healthier than him normally (compared to husband). The recommended practices also make me feel safer, so that's why I have confidence, maybe less worry or concern, less fearful. Therefore, I'm very calm in my mental health situation. So nothing panic about it. (\#19, 78 y/o Korean female, lives with husband in condo)

Well, I'm taking precautions, all the precautions like wearing face masks and washing my hands. We're changing the hand towels much more frequently and we use our own separate hand towels. We're taking these types of precautions to try to preserve ourselves...(\#13, 73 y/o Jewish male, lives with spouse in a condo).

I think [the recommended safety practices] are a precaution that's necessary. I think we have something we can do to make us feel more secure. I put coffee filters in my in my mask too and I change those to keep them affective, to keep the mask effective. (\#7,81 y/o Caucasian male, living with same-sex spouse in an apartment).

I'm really not that concerned if I catch it. I catch it, I'm hopeful that I would be able to pull through. I have a fairly good immune system, when I get a cold I do have asthma, and when I get a cold it does flare it up, but I've always managed to control it so it's not severe enough that it really would worry me." (\#14, 70 y/o Irish Jewish female, lives with husband)

I'm a statistician, there must be probabilities or risks for getting the virus, but the precautions I am taking is very low. (\#17, 77 y/o Middle Eastern male, lives with spouse in a condo)

"I try and take all the necessary precautions... but at the same time I do hear people get the COVID and they cannot figure out how they get it, so that can get me a little uneasy sometimes but it's not something I worry about, but in the back of my head I'm always saying well OK I'm doing everything right and everything I'm supposed to do, I hope that's good enough for me not to get COVID” (\#18, 78 y/o Black female, lives alone in a house)

Me contracting the virus, even though I know chances of that happening are pretty slim, but you know there's always that thought at the back of your head (\#15, 65 y/o Ukranian female, lives alone in house)

I try and take all the necessary precautions... but at the same time I do hear people get the COVID and they cannot figure out how they get it, so that can get me a little uneasy sometimes but it's not something I worry 
Infrequent worry

Concern for others about, but in the back of my head I'm always saying well OK I'm doing everything right and everything I'm supposed to do, I hope that's good enough for me not to get COVID (\#18, 78 y/o Black female, lives alone in a house)

Because I have an autoimmune disease and I have a disability and stuff, I'm more vulnerable than if I was 25 years old. I have to be more cautious and you know make sure that I'm following the social isolating, and washing my hands a lot, wearing the masks because, with the illness that I have I'm never going to be able to have the vaccine, because I got my illness from having a vaccine from the flu shot, so I have to really protect myself from getting COVID ( $\# 8,71$ y/o Caucasian female, lives with sister in co-op)

Say I'm having a bit of nausea because of my stomach surgery, sometimes I think 'Oh my God am I getting COVID' and then when I wake up I say 'no no no it's unlikely' (\#10, 72 y/o Celtic Jewish female, lives with sister in co-op)

The guidelines work. But I am a little bit of worried about getting [the virus]. Not through my own mistake but because of somehow who is not following the guidelines. That would be how I get it. Not because I'm irresponsible but because some other people are being irresponsible. (\#1, 75 y/o Filipino male, living with spouse and children in house)

My daughter's job has been affected you know like 100\%. I mean it's amazing the changes she's had to go through and right from the very beginning, she is in a very vulnerable job which has been a worry you know, she's more exposed from frontline workers (\#13, 73 y/o Jewish male, lives with spouse in a condo)

Because I'm asthmatic, I was wearing the disposable [masks], I really had trouble breathing. But I was determined to find a mask I could wear, and since then, we've found cloth masks that don't bother my breathing so much. I tried to find something that would work instead of just saying 'well I can't wear a mask,' because I feel very vulnerable with my autoimmune disease so, you know it scares me more than asthma death so I've found cloth masks work. I'm glad that I found that because I feel protected and I'm protecting other people from me too because, my mouth is paralyzed and a lot of times spit will come out of my mouth unintentionally, so I'm protecting other people when I'm out too... I have a good social conscience, I don't want to make anybody else sick and I don't want to get sick." (\#8, 71 y/o Caucasian female, lives with sister in co-op)

"I think [the recommended practices] should be mandatory... And the mask, my doctrine is I'm doing it for me for sure, but I'm also doing it for people that I don't know because what if I do have it? What if I'm a carrier and I don't have symptoms and I don't wear a mask? I mean the thought of harming anyone, yeah. That that that would be bad. (\#5, 74 y/o Caucasian female, lives with spouse in a house)

Because of my asthma, it is more difficult to breathe through a mask but, first of all, as a board member I feel that I should be seen to be wearing one as an example to the people that aren't wearing one, and second of all, it's my... I won't give it to anybody and hopefully if somebody else is wearing a mask they won't give it to me... you do as much as you can to make sure nobody does get sick and as of yet nobody in our building or 
the next door building have gotten it and there's a lot of older people here. (\#14 70 y/o Irish Jewish female, lives with spouse in a condo)

You know, I'm trying to do all the sensible things so I don't have to, and I don't pass it on. God forbid I pass it on to anyone, I think that would be worse than getting it myself. ( $\# 21,75$ y/o Jewish female, widow lives alone in condo).

Because I see young people are getting it, I see children are getting it now. That's a concern. (\#22, 65 y/o Caucasian female, lives with spouse in a house)

[As for my family] one is in [region of US] and another is in [different region of US], so I'm a little worried about their being safe enough to avoid [COID-19]. (\#7, 81 y/o Caucasian male, lives with same-sex spouse in an apartment).

I'm looking at all the people's livelihoods disappearing and ... the uncertainty of it all and you know children going to school and is it gonna be safe for them, is it gonna be safe for the families... (\#8,71 y/o Caucasian female, lives with sister in co-op)

I gotta be more careful as to where I go or who I see because I could be bringing it [the virus] to them [immune compromised spouse and mother in nursing home]. So if it was me on my own, it would probably be lonelier but I might be able to go out more, you know what I mean, because I would only having to worry about myself. (\#4, 69 y/o Caucasian female, lives with immune compromised spouse in a house)

Frustration with young adults From what I see everybody's following the rules, where it's the young people who don't seem to get it... They don't seem to take it as seriously. I've noticed other people's kids, in their 20s as well, jumping into cars with their friends and driving off, and I'm thinking 'oh my god' (\#22, 65 y/o Caucasian female, lives with spouse in a house).

I think it's good that we have to wear a mask when we go in close quarters... [Physical distancing] is hard to take some times. Like no hugging and all that. But it's good if it's a preventive method, you wanna stay safe right. I think you have to really follow the rules. I think, you know, you don't want the pandemic to get worse.... I say why would people go for their nails, it's not a necessity? That ticked me off a little. (\#2, 74 y/o Caucasian female, widow lives alone in condo)

I trust what the health experts say, and I know that advice is evolving. I mean, this is a new virus nobody knows everything about it, but yeah I'm fine with doing all of those things ... I'm a little bit annoyed that some people think that they shouldn't do it because of their own individual rights and, you know, it's just silly. I mean it's something in a case like this, I think individual rights get suspended and you have to do the right thing for everybody else. (\#3, 67 y/o Caucasian female, lives alone in a house)

What pisses me off is when I go grocery shopping, there are a lot of shoppers who don't wear their mask, or if they do it under their chin or below their nostrils. That really pisses me off. I went to the mall here yesterday and the 25-minute time that I was there I saw 15 people, either wearing masks improperly. I did take action and I wrote my counselor and he's actually passed my event onto the border of health and they're going to investigate the mall. (\#11, 74 y/o Jewish male, living with spouse in a condo) 
One of the things is you know, people that aren't wearing masks, and the social gatherings ... what you have on the beach, the park, or people having parties ... that may not affect me directly, but on the other hand it might because you know all you need is for one person to contract the virus and then pass it on, and pass it on, and pass it on, and there you go. (\#15, 65 y/o Ukrainian female, lives alone in house)

People who can take a 'it's not gonna happen to me' attitude and not pay attention to what good science is... bad science is one thing, evolving science is another... but when it's clear that distancing, washing hands, wearing a mask and not gathering in large groups works, why people on God's green earth think that they can be doing this appalls me. (\#16, 70 y/o Jewish male, lives with common law partner in condo)

I think it's important to highlight that the we need to be careful. We keep hearing about this coronavirus fatigue. We need to all still be vigilant and make sure that masks are worn and that you know, even if it's inconvenient and you don't particularly want to do it, people should be doing it." (\#14 70 y/o Irish Jewish female, lives with spouse in a condo) It's up to everybody in these times, to do their best, to protect everybody else...you know, I'm wearing a face mask not 'cause I'm going to be protected, because I'm protecting you, and vice versa. You need to help me by wearing a face mask as well and I think everybody is... looking around the world, you see the reports in Europe, in England, in America, Florida they're just frightening how people just don't seem to get it done. (\#13, 73 y/o Jewish male, living with spouse in a condo)

Fear for continues pandemic I don't think anybody's gonna be safe, nobody is going to be safe, until we have an effective vaccine... they say that people will have to carry badges or in some way identify themselves as having been vaccinated before we can relax any of these face masks or social distancing but I think that will be the only true end of this is that when we have an effective vaccine (\#13, 73 y/o Jewish male, lives with spouse in a condo) I worry about the future, especially the winter time and the 2nd wave. I hope that there will be some vaccine or treatment soon, before it gets much worse" (\#17, 77 y/o Middle Eastern male, living with spouse in house)

I would say that my biggest fear is that this is going to take a very long time and when we actually able to move around with freedom, it is not going to be the same in terms of safety for your health. (\#20 $67 \mathrm{y} / \mathrm{o}$ Caucasian female, living with spouse in condo)

I fear that the virus is going to continue... that we're not going to find a way to deal with it, like we're not going to find a vaccine early enough and the that this will just go on. (\#15, 65 y/o Ukrainian female, living alone in house)

My biggest concern is that we're going to get re-locked down... because there seems to be too many people that aren't taking this seriously at all. They have assessed the risk is so low that they don't have to do anything...perhaps it's not going to end until March of next year. (\#12, 70 y/o Canadian male, living with spouse in house)

I worry we will get a second wave, and it won't be in the fall, it will come this summer. And then we'll get a third wave. I guess that it will be never ending. ( $\# 22,65$ y/o Caucasian Caucasian, lives with spouse and children in house) 
I worry that things will not be as they were, that we won't go back, where there's going to be a total new normal in terms of traveling and being able to see people and be comfortable with people. I think that's my biggest concern... that just things will not be as they were. (\#6, 71 y/o Caucasian female, lives alone in house)

I don't know if we'll ever get rid of that until we actually have a vaccine for it. I'll be the first one standing in line to say phew, thank god we got through that one right. (\#4, 69 y/o Caucasian female, lives with immune compromised spouse in house)

codes

Standard of living

Fear messaging

Ageist fear messaging

Ageist fear messaging
Subtheme 2:

Financial Threat

My biggest concern is probably financial because I worry that my husband still works as a [occupation] and he needs to go to see clients and the clients aren't as busy. I am 70, they wouldn't employ me any longer and it's not, I mean, I worked as a [profession], I haven't lost that ability, but they just don't see it... in that sense, that bit upsets me and so I have to rely on my husband's income and on our pensions, and that it's tough. It's tough to live in a fixed income these days (\#14, 70 y/o, Irish Jewish female, lives with spouse in condo)

I have a financial concern, because I'm semi-retired...so I don't get pension income... and I'm concerned since my employment income is significantly lower than it was at this point last year. And I have taken advantage of the governments subsidise...but you know that's finishing this month (\#13, 73 y/o Jewish male, lives with spouse in a condo)

I'm a sole practitioner and at least for April and the beginning of May my work suffered terribly it was very challenging in terms of income and the word I use is discombobulating in terms of working a little bit at home, sometimes at home, sometimes in the office, and that was really challenging. (\#16, 70 y/o Jewish male, lives with common law partner in condo) My biggest concern ... that financially I can stay in my apartment, and I can afford it.(\#2, 74 y/o Caucasian female, widow lives alone in condo)

\section{Subtheme 3:}

Fear Messaging in the Media

I as a CNN junkie. I'm now not doing that because I don't think that's healthy either... I know fear of catching the virus is fueled by media coverage because now that I don't listen to it, like very little, I'm much happier. Yeah. I think at first it was just like it was like an addiction (\#5, 74 y/o Caucasian female, lives with spouse in a house)

Every time I watched the news I would just feel my heart sink a bit ... I wanted to stay informed as best I could, but I found that it just got to be too much so I limited it to twice a day probably (\#6, 71 y/o Caucasian female, lives alone in a house)

I think the media has a lot to do with people's fears... I think sometimes that the media plays it up. So sometimes it's good not to watch the news ... we're trying very hard not to get too excited about this whole thing. (\#9, 73 y/o Caucasian, male living with spouse in a house)

When it all first came out... a lot of what we heard was that it was going to affect 'us' more than anyone else, and that played on my brain a little bit.... all you heard was 'be careful of the', you know, 'it's the seniors' (\#5, 74 y/o Caucasian female, lives with spouse in house)

All we heard was it definitely is going to impact people over the age of 65 or 70, and stay home. Basically, we don't have enough ventilators for you 
Ageist fear messaging

Media lacking folks - you need to flatten the curve because you're the ones that are really going to put a stress on the system. I had a social obligation. Like, even if I did poke my head out the door it's like 'Oh my gosh people are going to know I'm over 65' and they're going to probably look down on me because I'm not in my house. So, for a while I was afraid to go out for a walk even (\#6, 71 y/o Caucasian female, lives alone in a house)

Everybody says that if you're 60 or older you are more in danger. I don't believe in living my life in fear. I mean, I know that I'm 70, but in reality most of the time, other than with my arthritis, I don't feel any different than I did when I was bringing my kids up... And my age doesn't, as far as I'm concerned... it's only a number (\#14, 70 y/o, Irish Jewish female, lives with spouse in condo)

At the beginning I was very concerned because they were saying that older people are being affected more, so yes at the beginning when it was said that older people have a lower immune system and it affects them at a higher rate, I was very concerned about that... so I always consider, OK, in in the case of an older person like me, I will try not to get COVID because I'm thinking, at 78 my immune system is not what it is at maybe 48, so I am concerned about the immune system issue of older people... that can make me a little unsettled so that's why I take the vitamins and stuff that says [it's] good for your immune system. (\#18, 78 y/o Black female, lives alone in a house)

Because of so many deaths of seniors, now it seems it's changing now younger people are more fatalities, so certainly the media impacts how I felt about this. (\#17, 77 y/o Middle Eastern male, lives with spouse in condo)

I think that people initially thought that the pandemic was an old people thing (\#13, 73 y/o Jewish male, lives with spouse in a condo)

Well [media message] gives you a certain isolation because of my age group. (\#2, 74 y/o Caucasian female, widow lives alone in condo)

I find that the news is not really giving us good information... we are finding that the information is not very clear at all, even with government websites, certainly not in the newspapers (\#13, 73 y/o Jewish male, lives with spouse in a condo)

\section{Subtheme 4:}

Living Arrangement Challenges

One of my ways of getting some sort of social interaction would be to go grocery shopping. I would go pretty well every day because I needed to.

Living alone That's the way I shopped, and so of course when everything was in lockdown, I couldn't do that and what I found was a greater sense of isolation (\#15, 65 y/o Ukrainian female, lives alone in a house)

That's the biggest thing for me is that living alone I have quite frankly started to name the spiders in my house. I don't really have a bubble. So that's the thing that I'm kind of missing. That everybody has made, created these little bubbles with their immediate family, 'cause those are the people that they really need. They need to bubble with, and I totally get that, but when I don't really have family in the city, it's harder for me to have a bubble. And that's the thing that I have found the hardest. (\#3, 67 y/o Caucasian female, lives alone in a house).

Even if something small broke down like my smoke detector.. it started beeping and I couldn't get anybody to come in to take the stupid thing down and put in a new one because no one was coming into the house 
Living with spouse

Living in small space and that was true for anything really, anything that you needed done. It's very much that feeling of helplessness (\#15, 65 y/o Ukrainian female, lives alone in a house).

I'm quite used to living alone, however during COVID, my support system was not there so I truly felt alone. [Before the pandemic] I could just go to the gym, go to the grocery store, do a little shopping and then come back home and be totally comfortable alone once again, but once those supports were gone I truly felt alone. (\#6, 71 y/o Caucasian female, lives alone in a house).

People in our condo who are widowers, and some of them have trouble coping with being alone. So even though we're not together all the time in the condo, we're in our separate rooms at times, you know that person is there, and you can discuss what you like about what they're showing on House Hunters or things like that, or have a friendly competition of answering the Jeopardy questions or Wheel of Fortune (\#11, July 14th, 74 y/o Jewish male, lives with spouse in condo).

"[My husband] is definitely the one that will talk me down from something. So if I say, you know, "What if?" He'll just say, "Don't what if it." Just, you know, we'll cross that bridge. He's a lot more sensible and not up and down like I am. (\#5, 74 y/o Caucasian female, lives with spouse in house)

I'm really really enjoying my wife more than I would maybe under normal circumstances because we both have our separate lives you know. (\#9, 73 y/o Caucasian male, living with spouse in a house)

My husband and I have always been close and we do a lot of things together, so yeah I mean I probably would not have coped nearly as well and I feel really sorry and sad for people that are completely alone. Just by having someone else, shall we say, to have to cook for and to have to think about, and then to argue with when the need arises. But I mean you know if you're completely alone there's nobody to talk to, and so I would think that that would be really, really difficult. (\#14 70 y/o Irish Jewish female, lives with spouse in a condo)

If I'd been alone I think it would have been a good deal more difficult to maintain a schedule and keep in high spirits because we get together on the balcony at night and we share the Netflix nonsense and you know it's good - it's been a tremendous help to have my spouse. (\#7, 81 y/o Caucasian male, lives with same-sex spouse in an apartment)

Well, we're not divorced and I think that's a bonus ...He'll go do stuff in the shop, I do my throwing around in the house, and if things get tense we both think, 'we'll just go for a drive', take a bottle of water with us, just go for a drive to nowhere and just come home, and we share a couple stories we like on TV, we have a good supper, and we can walk on our road... I'm glad he's here... just to know that there's someone else here and that makes me happy. Yeah, I'm grateful to have someone with me. (\#5, 74 y/o Caucasian female, lives with spouse in house)

I think it really made me appreciate the fact that I'm living with my sister and that I'm not alone as a lot of people in my co-op that have been really having serious mental health issues by being alone and being isolated and at least I have some companionship and we help each other out. (\#8, 71 y/o Caucasian female, lives with sister in co-op)

We're more cross with each other and I think that's just inevitable. we're together 24 hours a day, most of the time, and that's too much for 
anybody ( $\# 7,81$ y/o Caucasian male, lives with same-sex spouse in an apartment)

Now I spend more time with my wife as I'm not going out as much as I used to do before. I'm not travelling so we spend more time together. So we have sort of different interests... even, say we watch TV, we have different interests so we have to think and consider how to best turn this into a positive way. (\#17, 77 y/o Middle Eastern male, lives with spouse in a condo)

If you catch the virus, you need to quarantine yourself. But because of the construction of our townhouse. If one of us catches it, well then the person has to quarantine. But what about the other two? They might be in danger of catching the virus (\#1, 75 y/o Filipino male, lives with spouse and children in a house)

My husband would go to the gym 3 times a week, so that's out. And that makes him kind of grumpy. And this affects me because when he's grumpy it's unbearable. And I get really anxious when he gets grumpy. (\#20, 67 y/o Caucasian female, living with spouse in condo)

If I had been still in our home, I would have been outside on the porch in the mornings, talking to my next door neighbors, because we used to do that all the time... or I would have sat in the backyard and enjoyed the sunshine. In the condo, you have to get in the elevator, you have to go down the stairs, you have to wear a mask. (\#14 70 y/o Irish Jewish female, lives with spouse in a condo)

"We've got a big backyard, we're back on a ravine, so we've got privacy back there, we can go sit back there. We tend to sit out front, decked out front as well because the neighbors walk by and you talk to people. And its big enough so that we can have someone on the deck and still be social distanced by 6 feet. Which we do" (\#22, 65 y/o Caucasian female, lives with spouse in a house).

I have this porch. I've put my chairs at opposite ends so I have like a good 10 feet so that if somebody wants to come and chat with me they can feel comfortable about social distancing. A neighbor of mine comes on a regular basis and he sits at one end of the porch, and I sit at the other end of the porch and we can have a conversation. (\#15, 65 y/o Ukrainian female, lives alone in house)

We have one acre detached from a 74 acre farm. So there's no one on that farm, just cattle grazing. So we have this luxury of walking the road, sitting outback with nobody bothering us, and watching the cows have babies... and to keep up the garden... and I think we're busy and it's beautiful, other than the heat, yeah. I think we're blessed that way" (\#5, 74 y/o Caucasian female, lives with spouse in house).

I live in [rural area] so we don't have the congestion that you get in downtown cities. Also this nice big house on this big lot. In this relatively sparsely populated place. When we go for a walk, we have lots of room to avoid other people. If it weren't for the fact that you know we don't go out as much, we wouldn't know there was a pandemic. (\#12, 70 y/o Caucasian male, lives with spouse in a house).

We have a 2-bedroom condo. She has her own interests, she'll watch her TV programs... things that I'm not interested in. I'll go into the living room and I'll do crossword puzzles, I'll do reading, read a book read the newspaper, very rarely do I watch TV. Though we do spend time 
Living in a safe space together, there's also time where we don't, and it's just to get away from each other" (\#11, 74 y/o Jewish male, living with spouse in condo) Living in a co-op, I'm probably in a good environment where the rules are being kept by most people, there are some people with dementia that can't remember to wear masks, but on the whole you know most people are being very diligent about following the rules, so I'm probably safer here than I would be maybe if I was in a condo with a bunch of people that were a lot younger. (\#8, 71 y/o Caucasian female, lives with sister in co-op)

codes Subtheme 5:

The Challenge of Physical Distancing and Minimal Social Interactions Gone are the days sitting around eating a meal, going to the movies, all that stuff. I mean, normally we would like to get together, go for a walk, or a swim, and then go eat or have a coffee, and we would walk in the valley or somewhere nice. That's gone (\#20,67 y/o Caucasian female, lives with spouse in condo).

You get dressed up and go with another couple to dinner. You don't do any of that, and you miss the contact with people and the interaction itself is what keeps you sane you know. I know even in senior communities, like some of the nursing homes, they're so isolated that they need that human touch you know, and same with my friends. We're very huggy and touchy and now to see them at a distance is just really weird that you can't go near them, so yeah there's a huge difference I think in my life. (\#4,69 y/o Caucasian female, lives with immune compromised spouse in a house)

I've never really considered myself like a really overly affectionate person but I'm just really, you know, I've been out now for a massage and I went and had my nails done yesterday and I had my hair done last week and it's like just to have another person touch me has been fantastic! (\#3, 67 y/o Caucasian female, lives alone in a house)

One of my ways of getting some sort of social interaction would be to go grocery shopping. I would go pretty well every day because I needed to. That's the way I shopped, and so of course when everything was in lockdown, I couldn't do that and what I found was a greater sense of isolation" (\#15, 65 y/o Ukrainian female, lives alone in a house)

My social sphere is restricted dramatically... my life isn't noticeably worse because I don't get to spend a couple afternoons at the senior centre. Now for some people though, that's their whole world, and they're there everyday all day long (\#12, 70 y/o Caucasian male, lives with spouse in a house).

I want to go to a restaurant and eat with other people. That's my biggest thing now. Yeah I'm dying- and I want to get out of the city. I don't have a car. So it's more difficult for me to get out. And even if I get out, you know, where would I go because I don't know, you know, just because Toronto is still been kind of a hot spot. And a lot of my friends have cottages. So they just disappear for the summer. And usually I get invited to the cottage... but now, they're kind of isolating themselves at cottages. (\#3, 67 y/o Caucasian female, lives alone in a house)

I'm taking courses at [Learning Institute]. The last class ended at the end of March and now they're offering courses online and that doesn't really interest me because one of the reasons why I was taking these courses 
Missing social groups

Missing places of worship was for social interaction. (\#15, 65 y/o Ukrainian female, lives alone in a house)

"All my social interactions like my group that I'm involved with and volunteering at the hospital is all cancelled so that was kind of hard because you don't have any social outlets that way" (\#2, July 2nd, 74 YO Caucasian female, widow lives alone in a condo)

We miss seeing our friends. We would go to the Theatre a lot and to films a lot" (\#7, 81 y/o Caucasian male, living with same-sex spouse in an apartment).

I miss my outside activities you know the volunteer work that I was doing and the socializing that I was doing and my book group and, you know, all of those things. (\#3, 67 y/o Caucasian female, lives alone in a house)

I miss going to the pool - I did aquatic. And there's a group of ladies there that, I call them my peeps... I used to refer to it as my medical and travel group, because I would get all this information, and I was looking forward to getting back and doing that... So, I'm missing that." (\#22, 65 y/o Caucasian female, lives with spouse in a house)

I've been accepted as a volunteer and I've just started volunteering with them on Monday nights, you know a particular program I was going to and I was really enjoying that you know stepping up to the plate as a volunteer. I managed to go eight times and then suddenly the pandemic hit and they cancelled all the programs so that has been a loss for me in terms of social interaction. (\#13, 73 y/o Jewish male, living with spouse in a condo)

All my social interactions like my group that I'm involved with and volunteering at the hospital is all cancelled so that was kind of hard because you don't have any social outlets that way. (\#2, 74 y/o Caucasian female, widow lives alone in a condo)

My social sphere is restricted dramatically... my life isn't noticeably worse because I don't get to spend a couple afternoons at the senior center. Now for some people though, that's their whole world, and they're there every day all day long (\#12, 70 y/o Caucasian male, lives with spouse in a house).

I miss [going to community classes]. It was really nice especially since [I'm] living a pretty isolated existence. It was really nice to have a group of people that I could socialize with once a week. Sometimes two or three people would go for lunch. ... So I miss that, I do miss that. (\#15, July 28th 65 y/o Ukrainian female, lives alone in a house)

Social distancing, I think, is probably the one that has affected me more because I cannot go out with my friends, we can't gather together...it makes me a little sad that the things I used to do, go out and have a cup of tea or coffee with my friends, I cannot do that. Before COVID, after our church service maybe three or four of us will go for a coffee or we go for lunch or we do things together, and I enjoy that very much. (\#18 $78 \mathrm{y} / \mathrm{o}$ Black female, lives alone in a house)

Before the pandemic, I was in the synagogue twice a day and, you know, communing with a group of people... but some of it has had to be completely cancelled and I will say I have adapted, but it's still a big change in my circumstances (\#13, 73 y/o Jewish male, lives with spouse in condo). 
Missing family

Passover is a very very big meal. Even in the apartment, we've had 24, 25 people around our table. Well, this year, for the very first time ever, it was just me and my wife. Obviously we realized why, so we weren't depressed over it but... it was a big big change for us. (\#13, 73 YO male, Jewish, living with spouse)

I was an usher in my church but I have given it up. Ushering is something that I really like to do and chit chat with people at the back of the church, and yeah I think in a sense I have missed that. (\#18, 78 y/o Black female, lives alone in a house)

I miss going to church, I'll be honest. But they did open our parish and I chose not to be one of the ones that went back. I don't think it's time. I think it's too soon. I can watch it online. It's not as good, but it certainly helps. So that's a big part of my life because I'm very strong Catholic. (\#5, 74 y/o Caucasian female, lives with spouse in a house)

We cannot see our grandchildren up close and personal because, well because they [the parents] don't want us, they don't want to risk our being with the kids... It's so hard not to see them frequently but that's been a problem anyway because their parents are so busy with their life they both work and they have a huge circle of friends and you know we're kinda secondary to their lives right now so they don't invite us to see the kids very often and it's been an emotional loss exacerbated by the COVID thing" (\#7, 81 y/o Caucasian male, lives with same-sex spouse in an apartment)

My son and his family live in [city] and I don't get to see him this year. I don't know when I'm gonna be able to see them, and I think planes are COVID spreaders so it's probably going to be a long time before I would have enough courage to get on a plane. So that's something that I'm really missing, you know I've never spent this much time away from my son and his family before. (\#8, 71 y/o Caucasian female, lives with sister in co-op).

For the first couple months, it was just me and my wife, and there were some positive aspects to it, but of course we lost contact with family, and they weren't allowed to join us.... psychologically we're missing our contact with our family...I've got grandchildren, my son, his wife is strict over the whole rules and she hasn't stepped foot in our house since March... I wouldn't say it's me being depressed or anything but it's disappointing ( $\# 13,73$ y/o Jewish male, living with spouse in a condo) Especially at the beginning they all worried I might touch the virus from them so they didn't visit us as often, or even when they visit us it's shorter and they keep their distance. (\#17, 77 y/o Middle Eastern male, lives with spouse in a condo)

I can't go and hug my own grandchildren. My daughter-in-law won't let us, she was a hypochondriac to start with and this has just eaten into her I feel. I said to her the other week you cannot live your life in fear ... It really upsets me a lot that my grandchild doesn't know us and he'll never really know us the way my granddaughters do because he doesn't see us. Whereas funnily enough my son in [foreign country] makes a big effort with my daughter in law, a very big effort and they FaceTime us sometimes two or three times a week... so their son is younger than my grandson is here and as soon as he hears my voice he looks behind the screen to try and find us but he starts to smile, whereas I couldn't get a smile out 
Need for human contact

Need for emotional wellness

Life events of [name of grandson living close] here at all. And yeah I find that upsetting. (\#14, 70 y/o, Irish Jewish female, lives with spouse in condo).

Now, I'm a hugger. It's painfully hard for me to not run up and throw myself all over someone. I can do the elbow thing now. I'm learning. This is a day-by-day thing I will not lie. I'm not ashamed to say this. I have gone in the bedroom after the bed is all made later in the day and that [body] pillow is there and I have actually laid down and I've hugged it and I'm not ashamed to say that. And there is a little bit of comfort and, you know what, you take what you can get. Sounds ridiculous, but whatever works. Everybody should have a pillow (\#5, 74 y/o Caucasian female, lives with spouse in house).

Not being able to see my friends has made it harder for managing my post-traumatic stress... I have to be very careful about what I read and what I watch on movies or TV or whatever, that it doesn't trigger me so being in COVID and not being able to see some of the people that I miss has made it a little harder $(\# 8,71$ y/o Caucasian female, lives with sister in co-op).

Well, I live on my own now, which is a big change. So that's an adjustment for me because cooking for one... and what I do is I put the radio on as soon as I wake up, and that helps because somebody is talking, you know? I'm so happy for my radio. [My husband] didn't die of COVID-19 it was just his heart gave out, you know? In the hospital, I could not visit because of the COVID and so his decision was to have palliative care, which in a way was really good because he was with me, you know? ... I make sure I have a distance which is kinda sad in a way, but that's the way it is right, can't be hugging anybody... I find that very hard especially after a loss you know (\#2, 74 y/o Caucasian female, lives alone in condo)

I didn't retire because of the pandemic. It was planned retirement. It just by chance happened at the lockdown. I intended to work my last week at [industry]... and as soon as I came in, my supervisor told me to go home. He said I was high risk and so he said everyone was going home. And during that week I was supposed to have a retirement party - three of them scheduled for the last week. And so when I went home, everything was cancelled. I didn't get to say goodbye to my friends. Some of them probably didn't even know I was retired. Everything just went poof and it was gone. That is my disappointment" (\#1, 75 y/o Filipino male, lives with spouse and children in house)

I had a much older half sister who was in a nursing home and she passed away in May... So we haven't been able to have a service for her. But so that's been kind of sad that we couldn't have a service for her. I just had to do it [i.e., grieving] on my own. But I have to say I had a little bit of practice because my other much older half sister passed away in September. But she passed away the week I had my hip surgery. And I couldn't go to her funeral either because of that. I couldn't travel up to [location] for the service. So, I just had to kind of write out my grief and, you know, write out my memories and send it to her husband and her kids and so I, you know, so I kind of learned from that experience. With this- with my second sister passing away and so. But that's been hard because I lost both of them within the last six months." (\#3, 67 y/o Caucasian female, lives alone in a house) 
The guy who plays the organ, his mother died and I used to sit close to that woman all the time and I was so shocked that I could not go and pray with them at the funeral, and there was another guy again and two other people at different times.. So maybe I have grieved it in that kind of way because I could not participate to be there with the family. (\#18 78 y/o Black female, lives alone in a house)

My brother retired and that was a big deal and so we couldn't share it by being there. (\#7, 81 y/o Caucasian male, living with same-sex spouse in an apartment)

My husband would have travelled with the 3 kids for his mother's 90th birthday, and they missed that, so that was really hard... she's getting dementia, she's getting quite confused. So, he really wanted to be there soon. So that's really hard." (\#20, 67 y/o Caucasian female, living with spouse in condo)

My wife was admitted to hospital and for 12 days I couldn't visit her.... I was worried and I worried that she was feeling lonely, but then the procedure she had had a positive effect on her health so I'm glad with the end result" (\#17, 77 y/o Middle Eastern male, lives with spouse in condo). And during that week I was supposed to have a retirement party - three of them scheduled for the last week. And so when I went home, everything was cancelled. I didn't get to say goodbye to my friends. Some of them probably didn't even know I was retired. Everything just went poof and it was gone (\#1, 75 y/o Filipino male, lives with spouse and children in house).

Not missing it

In a way it doesn't bother me as much because I like being on my own sometimes, and quiet, and I don't need interaction constantly. I'm just happy to be with me. (\#2, 74 y/o Caucasian female, widow lives alone in a condo).

My social sphere is restricted dramatically... my life isn't noticeably worse because I don't get to spend a couple afternoons at the senior centre. Now for some people though, that's their whole world, and they're there everyday all day long. (\#12, 70 y/o Caucasian male, lives with spouse in a house)

I don't have that large group of people that I interact with anyway, so it's a small group... now there are days when I don't talk to anybody, okay, that's part of the impact of the pandemic. but it doesn't make me depressed, it doesn't make me angry it doesn't make want to lash out. (\#12, $70 \mathrm{y} / \mathrm{o}$ Caucasian male, lives with spouse in a house)

codes

Maintaining health routine

Transient health concern
Subtheme 6:

The Challenge of Health Management and Health Services

I am a member of the [community center] and that was my outlet for exercise [for my scoliosis]. I went to three-to-five classes for aquafit and I swam approximately a mile a week - that's gone. So I've been more than half a year without this wonderful exercise that made me feel a lot more energetic than I am now" (\#7, 81 y/o Caucasian male, lives with same-sex spouse in an apartment).

For a couple of weeks ago I was having some difficulty sleeping and I actually talked to my doctor about it and she had suggested that I try melatonin. ... I think it was just, not stress so much as just feeling tired of the sameness of it all. You know, just worn down a little bit." (\#3, 67 y/o Caucasian female, lives alone in a condo) 
At the early part of the pandemic, I had a difficult time sleeping, or falling asleep really, and then I get up and then I cannot fall back to sleep. Now, prior to COVID, I never had any issues sleeping. I try not to watch late news. Like, I don't watch the news late. But sometimes, maybe something dwells on your mind, like when people I know from our church died from COVID, and then you couldn't go and pray with the family, go to the funerals and stuff like that. When I hear of something like that it, I think, maybe within a day or two, it affects my sleep. (\#18 78 y/o Black female, lives alone in a house) You still get the intrusive thoughts but you don't have to act on them. But

Exacerbation of existing symptoms (OCD) I noticed it has been exacerbated during this pandemic (\#20, $67 \mathrm{y} / \mathrm{o}$ Caucasian female, lives with spouse in a condo).

What causes me to stay home is, number one, the depression; and number two, the chronic pain, because it's hard to move around. Just feeling of isolation, the feeling of, even if I wanted to go somewhere I couldn't, because it was locked down, it was closed, it was... you know, the feeling of that. The psychological stuff, the emotional problems, those really aren't under control. (\#15, 65 y/o Ukrainian female, lives alone in house) The fact that I have some anxiety, certainly the anxiety intensified because I didn't have the systems to be able to talk to. (\#6, 71 y/o Caucasian female, lives alone in a house).

Being socially isolated has been very difficult on my mental health, not being able to see my friends and family has made it harder for managing my post traumatic stress... Even before COVID came along I didn't like to be around a lot of people because I felt like I was more vulnerable with an autoimmune disease, because anytime I catch anything it makes my body go crazy and it starts attacking my nerves and destroying them. So anytime I step out of my apartment it's kind of a danger zone ... [ COVID19] certainly made me more conscientious of washing my hands every time I come back in the apartment, and you know very very frequently. I mean I always washed my hands a lot, but now I'm doing it even more. (\#8, 71 y/o Caucasian female, lives with sister in co-op).

My family doctor and I have had that chat on whatever system I don't know whether it was Zoom or not, but some sort of system. I'm supposed to have a checkup once a year, we did that over the Internet. I'm on

Health services a clinical trial with [*hospital name*], we did that over the Internet. My whoever he is for my colitis, we've done that over the Internet. I mean sometimes I wonder why I go see all these people! (\#9, 73 y/o Caucasian male, lives with spouse in house, liver transplant patient, ulcerative colitis, primary sclerosing cholangitis)

I had great support from the palliative care team [that supported husband] and I must say, I'm okay, the support was good. I'm lucky that I'm quite healthy, so I didn't have to go to too many appointments. And you know, most of my appointments are for my eye, and so one is cancelled because they were not very important, or delayed. So I was lucky to be in good health, so it didn't affect me much that way." (\#2, 74 y/o Caucasian female, widow lives alone in a condo)

I went off my blood pressure medicine and sent [doctor] a letter because he didn't even bother calling in, because I was getting the side effects of the pill, so that's been an adverse effect. And the idiots that are put in charge closed this clinic on [*location*] where we have tons of people that are fragile and frail. I have a psychiatrist that I've been able to video with 
and that's been good, although you know I would prefer face-to-face, but you know that's okay. And I still get my treatment at ["hospital name*] for my illness every 5 weeks. I was pretty scared going into the hospital for the first few times, but now I'm not as scared, I'm in this week again and you know I'm still a little scary going to the hospital. (\#8, 71 y/o Caucasian female, lives with sister in co-op).

My family doctor and I have had that chat on whatever system I don't know whether it was Zoom or not, but some sort of system. I'm supposed to have a checkup once a year, we did that over the Internet. I'm on a clinical trial with [*hospital name*], we did that over the Internet. My whoever he is for my colitis, we've done that over the Internet. I mean sometimes I wonder why I go see all these people! (\#9, 73 y/o Caucasian male, lives with spouse in house)

I used to go just over half a block away and go see my doctor and get appointments within the week and now you have to go through all these gatekeepers, you have to go through somebody on the phone that doesn't know you, and then I talked to the nurse who does know me and then she talked to the doctor and, you know, so it's levels and levels of bureaucracy to get to your doctor (\#10, 72 y/o Celtic Jewish female, lives with sister in co-op housing).

I used to go just over half a block away and go see my doctor and get appointments within the week and now you have to go through all these gatekeepers, you have to go through somebody on the phone that doesn't know you, and then I talked to the nurse who does know me and then she talked to the doctor and, you know, so it's levels and levels of bureaucracy to get to your doctor (\#10, 72 y/o Celtic Jewish female, lives with sister in co-op housing).

You know, I don't have any ongoing conditions. It was somewhat ironic, if you will. About a month before the lockdown, I suffered an injury. I split my kneecap in two after a fall. Yeah it hurts, and it was repaired, and I was immobilized for a bit. And I couldn't do physiotherapy after the pandemic started, so I missed some health care. It's recovering. Is it a condition that's chronic? No!. Is it treatable? Yes! And will it cure? Yes! But it's just...I mean, there are health care impacts, and none of which I considered to be catastrophic in any way. I'm back at the dentist, anyway. Some degree of impact, certainly not transformative. It was not transformative; manageable, manageable at best, at worst, inconvenient. (\#16, $70 \mathrm{y} / \mathrm{o}$ Jewish male, lives with common law partner in a condo)

I have had access to my family doctor. I have had a phone call with him, then I have also had a phone call with a specialist because my family doctor has sent me to a specialist...It did go well but I don't think it was sufficient... If I was sitting in his office, I'm pretty sure he would have asked me a few more questions. But the fact that I was not in his office... the next best thing is to send me for other tests".(\#18, 78 y/o Black female, lives alone in a house)

One of thing that I find really frustrating is that I cannot see a doctor [for chronic pain condition]. I can have a telephone appointment, but what I needed was for somebody to examine me... and it leads to a lot of frustration for me and a lot of anxiety and it's also hard to diagnose the problem." (\#15, y/o Ukrainian female, lives alone in a house) 
I feel that If I really needed my family doctor, she would figure out where I should go and what I should do. (\#20, 67 y/o Caucasian female, living with spouse in a condo)

I've had a Zoom doctor appointment and I'm concerned a little bit about how they've managed anything if they physically needed to see me. I mean, you know, when the doctor needs to see you in the office, he needs to see you, he needs to go put a stethoscope on you or put you on a blood pressure machine, he needs to feel internal organs and whatever and you know I have some concerns that that's going to be diminished. I did get a cat scan during COVID as well as an ultrasound, under suitable precautions, but again I think we've had some diminishment in medical attention, obviously they've been focusing on people who are much sicker. (\#13, 73 y/o Jewish male, lives with spouse in condo).

The pandemic hasn't affected my health, except, I have to get my pills at the pharmacy. For a while there you could only get 30 days at a time, which was to prevent a run on the drugs. But it also meant I have to go in more frequently. But other than that, it's fine. The medical system in Canada works for us." (\#12, 70 y/o Caucasian male, lives with spouse in a house).

I've had a Zoom doctor appointment and I'm concerned a little bit about how they've managed anything if they physically needed to see me... I think we've had some diminishment in medical attention, obviously they've been focusing on people who are much sicker (\#13, 73 y/o Jewish male, lives with spouse in condo)

codes

New for new learning

Need for assistance
Subtheme 7:

Use of Technology: A New Necessity

I've had to bunk up on my technology, I've had to learn how to do zoom, I've had to learn how to photograph a check and not go the bank... So, we're adapting to more of an online presence in our life, for everything banking, talking to people, zooms. I'm more terrified of going out in public than I am of technology (\#22, 65 y/o Caucasian female, lives with spouse in a house).

"It was a learning experience. I don't really one hundred percent like it as much. Like playing bridge online, or doing book club online, you know what I mean, it's not as nice as being in a group setting that you have each other, you know. It's okay... but I wouldn't like it to have it all the time like that. I don't want it to stay forever that way... In the meantime, I adjust (\#2, 74 y/o Caucasian female, widow lives alone in a condo). Some older adults don't have the means to really communicate. For example, they don't have computer skills, Zooming, and so on... Some need help, encourage them to be more active... help them find the means of communicating with others. There was one person but then she was adamant she didn't want to use the Zoom. She thought it's so complicated and she didn't have a camera, she didn't have a microphone. I really tried to push her and finally she is now happy that she is doing it, so there are people to help. I think for older people it's not only the medical and physiological assistance, they need some social assistance. Like you know providing them with all the new means of communication, computers, somebody goes and shows them how to use the Zoom, installs cameras, and so on. These people don't have the skill and some of them really not forthcoming they are not... because they think they are too old to learn 
Better than nothing

Unexpected benefits these new techniques (\#17, 77 y/o Middle Eastern male, lives with spouse in a condo)

Getting the internet set up was a little but no not too much stressful. Like, I had to call the company, like Rogers, several times and get them to help and come and set it up. And my nephew had to come and aid and get everything going with me. A little bit inconvenient but not stressful. (\#18, 78 y/o Black female, lives alone in house).

FaceTime was a great support, again being my age and not being used to the social media and how to navigate that was a process as well, but those supports were there and definitely definitely helpful." (\#6, 71 y/o Caucasian female, lives alone in a house)

It was a learning experience. I don't really one hundred percent like it as much. Like playing bridge online, or doing book club online, you know what I mean, it's not as nice as being in a group setting that you have each other, you know. It's okay... but I wouldn't like it to have it all the time like that. I don't want it to stay forever that way... In the meantime, I adjust (\#2, 74 y/o Caucasian female, widow lives alone in a condo). I don't get the same sense of encouragement on Zoom that I would on a face-to-face event. I mean it's better than nothing but I'm not a big fan of this new technology, I'd rather have an actual dialogue with people. (\#8, 71 y/o Caucasian female, lives with sister in co-op).

I have a very close friend and she is nagging me like crazy to do Zoom because she loves Zoom. I'm willing to try it just so that we can connect, but also because everything seems to be on Zoom. I should learn how to use it now, but I also should learn how to use it for what's coming up because everything seems to be on Zoom. But to say that I feel some sort of connection on it, absolutely not. (\#15, 65 y/o Ukrainian female, lives alone in a house)

I'm not loving zoom, but it's become kind of necessary I guess in all of this. (\#3, 67 y/o Caucasian female, lives alone in a house)

I used to play poker at the senior center couple days a week, now I can't do that and I don't like online poker it's not the same game. I'll play it when $\mathrm{i}$ am bored. Whereas on line bridge is still bridge. In bridge you play the cards you don't play the opponent, in poker you play your opponents, is not the same online. (\#12, $70 \mathrm{y} / \mathrm{o}$ Caucasian male, living with spouse in a house)

We both have our own laptop, so we can reading, listening, musical arts performance is more than before. Free, hahahah! Specially opera, which I am really fanatic about, and he likes the sports, so we have own time to do that without much boredom or anything (\#19, 78 y/o Korean female, lives with spouse in a condo).

The thing is we can't see them [i.e., mom in nursing home]. We could see them through the window, which is fine. But now you can't see them at all. So, this is what we do three times a week, I'm on Facebook with my mom, so thank God for that" (\#4,69 y/o Caucasian female, lives with immune compromised spouse in a house)

I do a lot of zoom meetings, I email a lot of friends...I read to my grandson, I read him a bedtime story every night on facetime. So, you try to do those things. And because I am a technophobe, for me, this is a lot. [COVID-19] forced me to do it because I want to stay in touch.... every Shebat we light the candles together, we make a blessing, because the kids would come to me for dinner every night. So, if I didn't learn to 
zoom, we wouldn't be able to do that. So practicality has formed me to do those kinds of things. I have to say that I've enforced the benefits of technology that maybe I would have not done before. (\#21, 75 y/o Jewish female, widow lives alone in a condo)

It's actually better in some ways because in book club, you get all these, it's hard to hold focus "let's talk about the book". You got these two over here talking and those two over there talking and you're like "excuse me, excuse me". So, it’s actually easier when you're all on a screen. (\#22, 65 y/o Caucasian female, lives with spouse in house)

I'm not even sure I found a big change. I love Zoom, I think that's wonderful, and so, you know, I probably use Zoom three to five times a week. I'm always interacting with people, not just people here, but all over the country, and sometimes all over the world... so I'm pretty happy with this. Yeah it is practical! This is an easy way to do business and I got a funny feeling that's not going to change a lot. So, you see you can teach old dogs new tricks! (\#9, 73 y/o Caucasian male, lives with spouse in house)

I downloaded the app on the phone that tells you if you're near anybody that has COVID. The app eases my mind maybe 10\% more [if not feeling well]...I'm so glad with the technology. Like, a lot of email. Like there's certain people that I know and our social relationship is sending interesting articles or videos and things, and I find that really helps me emotionally... and photographs, 'cause I love to take photographs, and then I send it to people and then I get the reactions back so that gives me great satisfaction. (\#10, 72 y/o Celtic Jewish female, lives with sister in co-op) I have a second son lives in [city] and with a new grandchild. We have met them, but now he's grown up, he's like almost eight months older than then. We see him like almost every single day on Zoom or social media, Facebook, whatever it is. So we get to see a lot of him but we don't get to hold him or cuddle with him. (\#13, 73 y/o Jewish male, living with spouse in a condo)

I mean to be honest, its kind of nice that all these speakers are coming to me, and I don't have to drive all over the place, or get on the TTC to hear this speaker, or that speaker. (\#20,67 y/o Caucasian female, living with spouse in a condo)

There's some benefits to online stuff. You don't have to go to the office to do this. I didn't have to go down there and meet you. In the old days, I booked an appointment, you'd have paid for my TTC or my parking, and we have done it. So your costs have dropped. Going forward in the future, will we ever have meetings where you'll introduce someone in the office? I don't know, is it necessary? So, part of the ease of going through the pandemic is the way we're all connected. Fifty years ago, how would you have done? (\#12, 70 y/o Caucasian male, lives with spouse in a house).

Theme 2: Coping with the COVID-19 Pandemic

codes

Mask wearing and other precautions
Subtheme 1:

Behavioral strategies

Because I'm asthmatic, I was wearing the disposable masks, I really had trouble breathing. But I was determined to find a mask I could wear, and since then, we've found cloth masks that don't bother my breathing so much. I tried to find something that would work instead of just saying 'well I can't wear a mask,' because I feel very vulnerable with my 
autoimmune disease. I'm glad that I found that because I feel protected and I'm protecting other people from me too because, my mouth is paralyzed and a lot of times spit will come out of my mouth unintentionally, so I'm protecting other people when I'm out too... I have a good social conscience, I don't want to make anybody else sick and I don't want to get sick (\#8, 71 y/o Caucasian female, lives with sister in co-op) Everything that we're doing like wiping down with canned goods and stuff and grocery store at first I just thought like this is insanity, but you know what it's just a small thing" (\#5, 74 y/o/ Caucasian female, lives with spouse in a house)

I feel I'm being a responsible citizen of planet earth by doing that, and also trying to educate myself as much as possible to ... understand what's going on and why we have all the rules and enforcing in your mind that it's not somebody trying to take away my civil liberties but rather me being a righteous responsible human being. (\#8, 71 y/o Caucasian female, living with sister in co-op)

I believe the physical social distancing, cleaning hand, to clean more surface.. I'm a chemistry major, so I really believe those directions. Very naive way, but [that is] only [what] they can suggest now without the vaccine development. So, I trust all the direction. If I follow, I am more safe. (\#19, 78 y/o Korean female, lives with spouse in a condo)

Minimizing media I think the news was pretty disheartening. So I do have a sense of what's happening. I mean I am happy that things seem to be turning around and fewer people are dying, which is very encouraging. But I'm not following it that closely" (\#21, 75 y/o Jewish female, widow lives alone in condo) I would get the newspaper and I'll look at the headlines... and I used to be addicted to $C B C$ radio. I was listening to that all the time, all the shows, you know. I would have it on all day. So that I've eliminated, and I think that I'm less anxious because of that. (\#10, 72 y/o Celtic Jewish female, lives with sister in co-op)

I don't watch the news now. I catch the headlines of an article on my iPad. I keep up on it enough that way, for me. I don't need the details every single day. It's too disturbing. (\#20, 67 y/o Caucasian female, living with spouse in a condo)

I realized after one or two weeks, that its not right. Nothing I can do, nothing we can do. So we both decided not to watch, limit our watch, so its make us for our better. Nothing we can do but why we keep listening. Yeah but two weeks wasn't right. Anxious to turn on news. Not like me at all. So I notice two weeks, no. News not going to lead my life. (\#19, 78 y/o Korean female, lives with spouse in a condo).

A curiosity in me that wants to hear or read what's going on about the disease....Not [listening to the news] more than usual. I normally do watch the news and I only get one newspaper on the weekend, so it's not more than usual but maybe I'm paying more attention. [Feels] sometimes a little unsettling. (\#18 78 y/o Black female, lives alone in a house)

I tend to be a bit of a news junkie and I love politics. I was perhaps watching the news more at the beginning, but then after a while I just went 'well, this is just the same old stuff now'. And I just realized that it was becoming too much. I think it just becomes a little bit overwhelming that I know my limits and I didn't want to get kind of swallowed up by it... it was just kind of depressing. (\#3, $67 \mathrm{y} / \mathrm{o}$ Caucasian female, lives alone in a house) 
Making a schedule

Pivoting
I was watching the Prime Minister daily at that point because I thought it was important. Because it was changing every day and you need to know how to conduct yourself, to stay safe and keep others safe. And then I decided I was going to stop watching. It's loaded ... it's too much, it's overload, too much news, too much information sometimes. That's why I shut it off... I feel overwhelmed sometimes when there's too much ...it disturbs your peaceful way of life sometimes. (\#2, 74 y/o Caucasian female, widow lives alone in a condo)

Every time I watched the news I would just feel my heart sink a bit ... I wanted to stay informed as best I could, but I found that it just got to be too much so I limited it to twice a day probably. (\#6, 71 y/o Caucasian female, lives alone in a house)

I try to make sure I have a schedule. I get up, I do a fitness routine, I get dressed, I have a zoom something in the morning or, you know I really try hard to make sure that I do have the structure. And I also make sure that I get out every day because I think, first, the fresh air, and also I'm very lucky, I live near a ravine, so I see lots of green, which is very important for me (\#21, 75 y/o Jewish female, widow lives alone in a condo). Each day I would have a goal for myself and usually when I do that I'm home, I get up, let's do this but let's get out, but I found that I really had to force myself some days to do things that that were on my list, so I did them but I didn't do them with a great deal of enthusiasm. (\#6, 71 y/o Caucasian female, lives alone in a house)

It didn't really impact my wellbeing at all, it was just a shift in what to do with my available free time. Instead of sitting around and moping, you know, I walked more, biked more, made it home more, watched the news. It's just a shift in how one occupies oneself, productively, stimulating (\#16, 70 y/o Jewish male, lives with common law partner in a condo). One activity I'm doing that I wasn't doing before, I started to learn to bake. I've started with scones, which I never did before, and we've been watching the great Canadian and Great British baking show, and that kind of inspired me to, you know, sort of challenge for me, so in a positive way that's affected that. (\#10, 72 y/o Celtic Jewish female, lives with sister in co-op)

Now that I'm not going to the gym, I do a lot more artwork than I used to. I've gotten - what do you call it - a portfolio started, and I also have run into a wonderful puzzle from in the globe. The artwork is a source of anxiety relief and they're both a lot of fun. The garden has been a tremendous comfort to counteract all that other negative stuff. (\#7, 81 y/o Caucasian male, living with same-sex spouse in an apartment)

I'll bury my head in a book or I'll watch another soap opera on TV to just ignore what's going on. I mean I do have a balcony and what I was missing was not growing anything, so I solved that by buying a hydroponic system. And it's interesting 'cause my husband thought I was crazy until he started to see everything grow, and then like me, he felt the same way. It's somehow reminds you that there is a world outside and that life goes on. (\#14 70 y/o Irish Jewish female, lives with spouse in a condo) One positive aspect is that I sort of did activities that I wanted to do before but didn't have the time, like trying to improve my language and my voice... I've been doing these online training for voice and accent reduction and so on. (\#17, 77 y/o Middle Eastern male, lives with spouse in condo) 
Keeping busy

Importance of being self-directed
Gardening, I think, takes my mind off a lot of other things, cuts about the weed. I think that's all healthy stuff... I think our busyness helps (\#5, 74 y/o Caucasian female, lives with spouse in a house)

All kinds of things are popping up in my head that now are filling time for me. I think the more you open your mind to what you could be doing, the pandemic takes a little back seat for that while. Gardening, I think, takes my mind off a lot of other things, cuts about the weed. I think that's all healthy stuff... I think our busyness helps. (\#5, 74 y/o Caucasian female, lives with spouse in a house)

I try and keep myself busy all the time. If I'm not doing something, I'll get bored, and if I get bored, I'll want to sleep. I'm involved in a couple of businesses, I stay very active that way. We do most of our walking in the morning, if it's a nice day. We'll walk in the afternoon sometimes, and I'll be honest our deck overlooks a walking path and we see a lot of seniors walking. They walk and they walk and it's a way to break up the monotony of being indoors. (\#9,73 y/o Caucasian male, living with spouse in house)

I'd say I'm filling the time. I wouldn't say I'm compensating. I say, what do I want to do? I think I'll go watch that. I like watching just mindless YouTube videos. You know, not everything has to be meaningful... So yeah, our media is up [since the pandemic started]. (\#12, $70 \mathrm{y} / \mathrm{o}$ Caucasian male, lives with spouse in a house)

We started watching these redecorating shows, or baking shows that are really fun that make you laugh. And we've been watching series that's really making us laugh and that kind of thing. So we went through it and we saw things that we really liked and we picked funny things so yeah that was a positive thing. ( $\# 10,72$ y/o Celtic Jewish female, lives with sister in co-op)

If I literally have nothing to do, then I'm... you know I'll find things to do. I read a book or something. Because of the pandemic, I've now been able to go out almost every single day like five, six days a week, and I'm walking five, six miles a day, and that's been very positive. (\#13, 73 y/o Jewish male, living with spouse in a condo)

I have more time for myself now - to do whatever I want to do. I have more things to do now. (\#1, 75 y/o Filipino male, living with spouse and children in house)

Well because it's like you have no purpose, like you can't go do the things you normally would do, you know, like you know, on a Monday I did this, I went here and I... all that stuff I can't do. I can't socialize with a group of friends and go play cards or do whatever because we can't do it right now, you know, so anything you planned or look forward to, you really can't do, you know (\#4,69 y/o Caucasian female, lives with immune compromised spouse in house)

I feel like, you know, now is a hard time to get started on doing something if you've never had an interest in doing those things before. So, I feel very grateful that I've always had the ability to be able be quite selfdirected in that way. You know, I can't go to the gym, I can't go to the museum. So, I've been doing a lot of sewing - I was making the masks, I've made three quilts, I made a tooth fairy pillow for my little nephews, I've been reading more, I found a couple of free websites through the library that has some really great movies on it. So, I've been watching movies and I've been painting my patio furniture. So, I've had lots and 
Physical activity

Being outdoors lots of things to do in my kind of free block between my breakfast routine and my night routine. I've set up a little exercise routine for myself every morning and I'm a lot, you know, I was never really too good at exercising at home, and now I've got this little routine and I'm quite, you know, relentless about it... So I've added that in and I think that that's been really positive" (\#3, 67 y/o Caucasian female, lives alone in house).

We do most of our walking in the morning, if it's a nice day and by that I mean 24-25 degrees, we'll walk in the afternoon sometimes, and I'll be honest our deck overlooks a walking path and we see a lot of seniors walking. They walk and they walk and it's a way to break up the monotony of being indoors ( $\# 9,73$ y/o Caucasian male, lives with spouse in a house).

I try to stay active, you know, like trying to do my ten thousand steps each day, sometimes I'm short you know you make do with what you have. (\#2, 74 y/o Caucasian female, widow lives alone in a condo) I still try to do things that I was doing before the pandemic, you know. Even though I might go for a walk and I know my knees are gonna be ached, I'll still go out. (\#11, 74 y/o Jewish male, living with spouse in a condo)

We had very good exercise classes twice a week, and now since the COVID we haven't been able to do that, and you know, I'm really really missing that. [The instructor] was very good at giving gentle exercises and stuff and I'm missing that and now my blood pressure has been getting higher because I'm not exercising as much. So now I'm trying to get up early in the morning and go for walks before it's too busy out there and before it's too hot too, so I'm trying to get my pressure more under control too. ( $\# 8,71$ y/o Caucasian female, lives with sister in co-op).

I started to feel isolated. I started to feel really sick of this. Yesterday, I started to think that this could be a really long time and I'm really sick of being stuck at home. So, I'm sort of sitting with that, and mostly ignoring it, hoping that it passes when I keep busy. Now that its nicer, we' re outside on our balcony. It's only a 4-story building and we're on a quiet lane with a garden and a whole lot of trees, so it's really nice out there and we're not on the sunny side, so now we can be out there comfortably. (\#20,67 y/o Caucasian female, lives with spouse in a condo)

The garden has been a tremendous comfort to counteract all that other negative stuff (\#7, 81 y/o Caucasian male, lives with same-sex spouse in an apartment).

Subtheme 2:

Emotion-focused strategies

You have to kind of believe that it's going to be OK because I think if you're a negative person and you just go to bed at night and go you know it's all for naught. Well, that's tough. I think that's a hard way to live, and I think that's going to make people ill (\#5, 74 y/o Caucasian female lives with spouse in a house)

I make the best of whatever I can do, always have. I've always, shall we say, risen to the occasion, no matter what it is, whether it's some kind of an emergency or whether it's this. (\#14 70 y/o Irish Jewish female, lives with spouse in a condo)

I think the more you open your mind to what you could be doing, the pandemic takes a little back seat for that while... We're both ice cream people, so we just go get an ice cream and sit in the car and eat it and 
Acceptance

Mindfulness

Perspective taking come home, you know. I think you have to pick your pleasures. They're little, but they're not as little as they used to be. Now getting an ice cream cone is a big deal (\#5, 74 y/o Caucasian female, lives with spouse in a house)

If I die, I die. I mean at this age it's kind of moot as to whether or not and it's gonna happen and I'm sort of resigned to that fact. I've had cancer, I'm now not getting enough exercise which I think every day lessens my chance of a longer life, but it's all sort of, you know, benign acceptance rather than intense worrying. I've had a wonderful life and I don't really mind that I'm closer to death than most people are. (\#7, 81 y/o Caucasian male, living with same-sex spouse in an apartment)

I'm not apprehensive so much as accepting that it [subsequent wave] will happen and to just work my way through it when it does. (\#14, $70 \mathrm{y} / \mathrm{o}$ Irish Jewish female, lives with spouse in a condo)

$I^{\prime} m$ just so grateful that I did have a home over my head, I had lots of food, financially I wasn't stressed, so I'm very happy about that. Laughing with people again, that made a huge difference just to be able to kind of put the pandemic on the background and sit and FaceTime or text and laugh. (\#6, 71 y/o Caucasian female, lives alone in a house).

We're just trying to figure out how we all move forward and what that will look like. And, there's moments when I worry about it, but I don't have any control over it, so whatever will happen will happen. I look at it that way. (\#22, 65 y/o Caucasian female, lives with spouse in a house) Mindfulness really helps if something's not going right. Especially if somebody's saying something or the situation, don't rush into it with your first reaction. Try to think about it first. That has helped. (\#11, 74 y/o Jewish male, living with spouse in condo)

You don't have to be brilliant, but just a strong mind that can say, 'I'm not going to do this. I just I need to concentrate on the joy, whatever joy that is. (\#5, July 10th, $74 \mathrm{YO}$ woman, Caucasian, lives with spouse)

I tend to be a very positive person and because I' $m$ also used to living alone, it's not as big a change for me... I've had enough tragedies in my life that you see, different people adapt to things differently. Sometimes when you're faced with a difficult situation you grow; other times you just fall apart. Because I've been through a lot of things I try to reach out to people who might need a helping hand because, again I really am very lucky. I have wonderful family and friends, and it really makes a big difference. (\#21,75 y/o Jewish female, widow lives alone in a condo) We came here at a vibrant age. Immigrant here. So we face difficulty in mid-20s. So maybe not like pandemic COVID-19 hardship, we had already hardship without the language, plus some level of racism and then during that time I was pregnant (\#19, 78 y/o Korean female, lives with spouse in a condo)

Transplant patients have learned to look after themselves... and so I don't know! I guess I'm so grateful to be alive that I'm going to enjoy every minute of it. The gratitude that I have today is much greater than I ever had before.... possibly the experience that I've gone through, I've had a second chance at life, like I should be dead, right?... and so you have a choice, you can either bounce off the walls or you can enjoy what you got! Yeah we're living through a tough time right now, you have a choice to enjoy it or not, I choose to enjoy it (\#9, 73 y/o Caucasian male, lives with spouse in a house) 
I think it brings people more together if that makes sense... Change isn't easy right, so any change you face, you have a little bit of stress from it, but you try to overcome it and see the positive side of it. The pandemic does not give me anxiety, not really... Because I went through life with something that was a lot harder than the virus. Like, I had leukemia, and that was really hard. I overcome that, and so, because I overcame already that, I'm more prepared to overcome anything. (\#2, 74 y/o female, Caucasian, widow lives alone in condo)

We came here at a vibrant age. Immigrant here. So we face difficulty in mid-20s. So maybe not like pandemic COVID-19 hardship, we had already hardship without the language, plus some level of racism and then during that time I was pregnant (\#19, 78 y/o Korean female, lives with spouse in a condo)

I think the pandemic [is] secondary to [husband's] cancer. I mean we just got through that, we just got told there's no cancer and then the pandemic came around. The pandemic isn't worse than his cancer was ...the pandemic is something we'll get through and it doesn't affect me half as much as his cancer would have, because I know this will pass and life will go on. You know what it's like, life gives you all these things, it throws all this stuff at you. This pandemic isn't the worst thing that it threw at me in my lifetime. (\#4,69 y/o Caucasian female, lives with immune compromised spouse in a house)

Our grandparents were refugees, and their parents had to deal with the pilgrims, and they had to come here with a suitcase. Also, in the Irish side, our grandfather came here and his father died ... I think our family has ingrained in our DNA 'just get on with it, and do what you have to do to keep on going,' and I think that really helps in the pandemic time." (\#10, 72 y/o Celtic Jewish female, lives with sister in co-op)

I really feel a lot for young people because they're so full of energy and I'm easily exhausted, so I don't think it's as big a sacrifice for me to have to isolate as it is for somebody that- or if you're home with five teenagers trying to contain all that energy." (\#8, 71 y/o Caucasian female, lives with sister in co-op).

Relative to what humanity has suffered previously, this is really no big deal. From the First World War to the Spanish flu, to the stock market crash, to the Great Depression, to World War Two, to the Korean War, you know. What have we got to complain about? Maybe I am naively optimistic, so I have some degree of hope that the pandemic, the virus will become manageable, either by vaccine or treatment (\#16, 70 y/o Jewish male, lives with common law partner in a condo).

We haven't had all the negatives that other people have experienced, we don't have little kids to worry about we don't have to homeschool, we don't have to worry about if we're going to keep our jobs. My age is such that I don't have the physical infirmities that will cascade upon me when I hit 85 or 90 . I' $m$ in that lovely part of the seniors spectrum where I've got all the advantages and none of the disadvantages. It's just a lot of time at home, but other than that I haven't been affected by it. Neither my wife nor I have had our income affected by the virus, so there's been no economic impact on us. The time pressure seems to be less. Nothing I'll get to today, I'll get to it tomorrow. I'll cut the grass today or maybe I'll do it tomorrow. (\#12, 70 y/o Caucasian male, living with spouse in a house) 
Hardiness

Meaning making
It's given me a different perspective on things, on what things are truly important. Small things that you take for granted that are important to your well being, a different perspective on that, I'm so grateful for those things (\#6, 71 y/o Caucasian female, lives alone in a house)

I've always been like, in my whole family, I've always been that balancing act for people you know... like I have siblings, when it comes to taking care of parents and stuff, they didn't do well with that, but I was always the number one guy they called. (\#4, 69 y/o Caucasian female, lives with immune compromised spouse in a house) It's just part of my personality, I don't give into fear. You know, even in earlier times in my life when I had back issues, for example, and you know like I was bedridden for awhile, but I just wouldn't give into it, you know. I just felt like, 'OK, well let's figure out a way to recover from this and get on with life', right. I just don't give into that kind of thing or if I've had you know bad things happen, I won't live my life in fear. (\#3, 67 y/o Caucasian female, lives alone in a house)

There is a COVID-19 pandemic versus a racism pandemic. But this COVID-19 pandemic gave me more voices about the decision... I have more facts to [relay] to other people in my community who are kind of ignorant with subtle racism underneath. So, we need more education about it. Its all relatable. Its nothing separate issues $(\# 19,78$ y/o Korean female, lives with spouse in a condo).

Well, you have to survive, right, so that's a lesson I learned to be sure. To look more properly after myself the best I can. I think it makes me stronger, yeah it makes me stronger. It's up to you to make the best of everything in any situation, you have to try to find the best; make the best for yourself... You find your inner self more, you're more in tune with oneself; you enjoy more reading because you have more time for all that; have more time to read, to just be, you know.." (\#2, 74 y/o Caucasian female, widow lives alone in condo)

My brother and me we exchanged meaningful letters about our life dependency on one another and my sister and I talk about it, my brother doesn't like to talk but he likes to write and I like both... so the pandemic has been a very ambivalent kind of situation. Both wonderful and terrible at the same time... Also, I am feeling a lot more responsibility about getting regular exercise. When I started, I was going to the gym because it felt so good and I lost a lot of weight in a year and a half. I've tried very desperately not to gain any weight back and, as I tell you, I've failed on that. It showed me that I will no longer think of it as just something I like doing but something that I have to do... I'm going to have to do this on a very regular basis not just as I wish, not on a casual basis. (\#7, 81 y/o Caucasian male, living with same-sex spouse in an apartment)

I feel there is definitely more [racism], and that I do have to say really concerns me. I've seen some awful stories about Jewish people started this, but I don't think it's any worse about the stories about the Asians and I'm really upset about that, that in this time when we really should all be working together, that something like this is happening, especially in a country like Canada. You've heard so much about the nursing homes and the inadequacy there, and that really troubles me, and also the homeless, and I think that those two conditions have really not only come to the floor, but really point out that as a society we really haven't been very compassionate and I think that's really important. And I've written 
lots of emails because I don't want this to be forgotten. It has heightened my awareness both of how lucky I am and also I've tried - because I do feel I am in a privileged position - to really contribute to people who might need a helping hand, like phone calls, and also financially. (\#21, 75 y/o Jewish female, widow lives alone in a condo)

I'm all for the distancing, I'm all for the plexiglass they put everywhere, I hope they always keep that even when this is all said and done. But I think it's been a really good lesson learnt for the whole country that all you really need to do is wash your hands and cover your face when you're. I mean it's common sense and yet look, it took a pandemic for us to do it. (\#4, 69 y/o Caucasian female, lives with immune compromised spouse in a house)

Silver lining

People have stepped up to the plate to try to adjust to new circumstances and they've done remarkably well in my opinion...this challenge [the pandemic] has really made us see what wonderful people that we have in our community (\#13, 73 y/o Jewish male, lives with spouse in a condo).

A friend and I were talking about it the other day and we were saying that, some of the things that have changed have changed for the better. People may be a little more respectful or people are more concerning about other people, that kind of thing. (\#18, 78 y/o Black female, lives alone in a house)

One insight is the ability of people, regardless of what they do, whether they're leadership governmentally or volunteers, is the ability to be creative. I'm actually quite impressed...How to move from speaking in person to doing it online for example... how some entrepreneurs have been able to take their industry or what they do in their industry and move it to something that is globally necessary in terms of health care or how, for example, the city Toronto has been able to make streets more friendly to bicycles and pedestrians, expanded patios whether it's going to be successful or not doesn't matter, it's just the creativity involved in doing that. (\#16, 70 y/o Jewish male, lives with common law partner in condo)

codes

Being connected

Supported by spouse and family
Subtheme 3:

Social Support

So, part of the ease of going through the pandemic is the way we're all connected. Fifty years ago, how would you have done? (\#12, 70 y/o Caucasian male, lives with spouse in a house)

He's definitely the one that will talk me down from something. So, if I say, you know, “What if?” He'll just say, "Don't what if it." Just, you know, we'll cross that bridge. He's a lot more sensible and not up and down like I am (\#5, 74 y/o Caucasian female, lives with spouse in house). I don't feel isolated like a lot of people do, and I feel like I have this support there, because you know we [sister] get along really well and we help each other out when needed you know? (\#10, 72 y/o Celtic Jewish woman, lives with sister in co-op)

The only family I have in the city other than my husband is a niece. And she offered to bring me stuff if I needed it. But you know, I realized that we're going to need to be self-sufficient if we weren't going to figure out this whole shopping online business, and it seems more important to be able to pick our stuff. (\#20,67 y/o Caucasian female, lives with spouse in condo) 
My daughter lives locally and they've been amazing in terms of shopping for us, particularly shopping you know, running messages for us. (\#13, 73 y/o Jewish male, living with spouse in a condo)

I did get support from family and friends, and even my neighbor, my neighbor brought me food twice" (\#18, 78 y/o Black female, lives alone in a house)

I had my 70th birthday during the pandemic. I had a great zoom party. My wife had a great takeout and homemade dinner and my wife and son put together an amazing video of clips of friends and family who had comments to make to me and about me on becoming 70. (\#16, $70 \mathrm{y} / \mathrm{o}$ Jewish male, lives with common law partner in condo)

They [my family] supported me in ways like, if you want something they would offer to go do the groceries or do something for me. But I was able to do those things for myself and I wanted to do them for myself...when I got the laptop, one of my nephews was very attentive in helping me set it up. I did not even have to ask him for help, he would call me and see, how is this working and so on. (\#18, 78 y/o Black female, lives alone in house).

I was 72 when the pandemic started, my wife was just, she just turned 70, and all of our children were very, very concerned about us, following the guidelines, and going out as little as possible .... and we tried to obey, you know, especially in the first couple of months. Especially with [my] diabetes, all of my children were very insistent, almost being a lot stricter than we are now in terms of going out, and so they volunteered to do our shopping for us" (\#13, 73 y/o Jewish male, living with spouse in condo) We communicating more often. They are concerned about us, because of distance and I am concerned about them because of distance. And then I think bottom line, maybe we both care. "They arrange whatever they can do, they send the groceries... the older daughter sent a care package with very fun snacks. (\#19, 78 y/o Korean female, lives with spouse in condo) I'm very fortunate to have a daughter of my four children close by and that helps a lot. She's been a great support and also my grandchildren help a lot. (\#2, 74 y/o Caucasian female, widow lives alone in condo)

Support from friends and neighbours I was very happy with the support and again porch drop offs, friends and work, my work colleagues did a couple of porch drop offs, we would FaceTime as well." (\#6, 71 y/o Caucasian female, lives alone in a house) I do have some good friends in the condo, and there's a group of us that have stayed together and we call it our own bubble and we play either a card game or Mahjong online at least twice a week, sometimes more, so it helps all of us. There's a particular person that I've become quite close to, and she went out to a particular bakery that I like today, and she brought me back a pile of bagels to put in the freezer, and as I said to her 'well I'm shopping tomorrow so if you want I'll pick anything up you need' and we do it that way. (\#14 $70 \mathrm{y} / \mathrm{o}$ Irish Jewish female, lives with spouse in a condo)

We live on a street where we have a great community of adults. [Many of us] kind of hang out together. We had a get-together where there were 6 chairs on one lawn. But we have four lawns that we can spread out on. So, we still see people. And we've had a street zoom a couple of times too, just with all the neighbors, like for different birthdays...Y You have to have those people to vent with. I think if you didn't have that, you'd be in a health crisis. If you're older, alone, without those people to talk to, 
just some to bounce something off of. Just to vent or to yap, or to share a concern. (\#22, 65 y/o Caucasian female, lives with spouse in a house) And there's a lot of phone calling: 'Well I'm going into [town] today, do you need anything?' It's just maybe three women sharing three different feelings, and most of those conversations end up in all four of us, being a whole lot better because, you know, you're not the only one feeling it. You know, you're not the only one that doesn't have the answers, and that gets scared sometimes... But I find my outlet with my friends always makes me stronger and I think we all hang up and go, 'Yeah I can do this. I feel better'...And our daughter and our sons will come up, you know, and still socially distance but at one time they would just come out and park in the driveway and we would stay in the sunroom and just yell, ‘We're fine'. (\#5, 74 y/o Caucasian female, lives with spouse in a house) We call ourselves the fab five (laughs). We all became friends. Every time after choir, it was in the afternoon, and we would go for coffee or lunch, and chat for hours. And we have been zooming about every other week, which is really nice. I look forward to those things. And we don't necessarily talk that much about COVID-19, you know, we talk about it and get it out of the way and then we each talk about what we've been doing, what we've watched on Netflix, what we're reading. Stuff like that (\#20,67 y/o Caucasian female, lives with spouse in condo).

I'm really happy for my neighbors where I live. We help each other in a small way, by leaving things at the door, and you know, sharing stuff, you know, food if they run out of something. I would feel so different if I was all by my little self and nobody, you know what I mean. Like but we still have a community and that makes such a difference, it's not like we have total isolation you know? We check on each other little more, you know, by phone or something, you know, to see how we were doing, you know?" (\#2, 74 y/o Caucasian female, widow lives alone in a condo) I feel very connected with people in the neighborhood. In the market, I think they know me well enough. When I go to the tents at the farmers market, the guy that polices the door knows me and just lets me in and I don't have to line up around the block. So in that sense I'm getting a positive out of it. (\#10, 72 y/o Celtic Jewish female, lives with sister in coop)

We don't have access to our library, so no reading from the library. But we still help each other with books that we give each other, you know, we pass on to each other, which helps...I have Bridge group and I have a knitting group. We meet quite frequently. And also a book club, that we meet and discuss our reading. ( $\$ 274$ y/o Caucasian female, widow lives alone in condo)

It's just maybe three women sharing three different feelings, and most of those conversations end up in all three or all four of us being a whole lot better because, you know, you're not the only one feeling it. You know, you're not the only one that doesn't have the answers, and that gets scared sometimes. But I find my outlet with my friends always makes me stronger and I think we all we all hang up and go, 'Yeah I can do this. I feel better' (\#5, 74 y/o Caucasian female, lives with spouse in house) We keep in touch, like calling each other, not necessarily on a daily basis, but we do keep in touch with each other by calling each other and chatting. At the beginning we were doing it a little more frequent, but over the months we have been a little less frequent but I feel confident 
Need for more support

Supporting others that I can call my friends or they can call me, and we can get in touch. (\#18, 78 y/o Black female, lives alone in a house)

I am always wishing for more support and I, so that's you know, that's an ongoing theme for me...my hopes and my wishes for you know social interaction and for people, you know coming to take care of me is unrealistic, and it was unrealistic before the pandemic. It's great that my brother would come every Saturday but I also wanted him to phone me twice a week. Or even my friend in [city], I would hope that she would call me more than once a week ... I think people have their own lives, I don't think that's completely realistic but that's what I would want (\#15, $65 \mathrm{y} / \mathrm{o}$ Ukrainian female, lives alone in a house).

Father Vincent [pseudonym] sends me little jobs... my capabilities on the Internet are limited and he knows that so he'll give me a list of calls to parishioners and just say 'I'm calling on behalf of Father Vincent who just wanted to know how are you doing? Do you need anything?' You know, so that's a blessing. 'Cause if you call 5 people in a day and you help one person who's alone and say to them, 'Listen, I'm calling on behalf of the perish, but you can have my phone number, and if you just wanted to chat you know I'm home, I'm stuck here too'. I've had a few calls, and I have to tell you, if you ever think that that's not a blessing, you're crazy, because that will take your mind off anything that you're feeling. A couple of times, I talked to a senior, and I don't know if I made them feel better, but I felt better. It was like I was talking to me (\#5, 74 y/o Caucasian female, lives with spouse in a house)

We have a small group of people who will come over, and like this afternoon my wife is having three people come over and play cards and they'll have dinner here. I'll go up and join them for dinner, and yeah, I think all of them are single and they're just dying to get out, and they're social distanced so we have a very small group of people that we work with... they are very appreciative of being able to get out and come over and stuff like that and I appreciate seeing them. (\#9, 73 y/o Caucasian male, lives with spouse in a house).

I've always being computer literate, so I'm one of these ones that will help other people do it. I have friends here in the building that, when something goes wrong with their Gmail, or they need to write something, or they don't know how to find something, I get a phone call: 'can you come down and help?' (\#14 70 y/o Irish Jewish female, lives with spouse in a condo)

I have [community organization]. I have created my circle, including group I started of senior group members. So what I've been doing, I keep trying to make not only social gatherings, I keep contact with them regularly. I'm planning an emergency directory, I'm planning to develop, how I can reach out to those who needs a hand, for when another pandemic or emergency comes here. So, I'm working on it. The [community organization] accepted my idea. I believe we are not alone. You have to work together (\#19,78 y/o Korean female, lives with spouse in condo)

In my synagogue, I'm one of the phoners who keeps in touch with elderly members of our congregation. I would say, before these phone calls I did not know many of these people. But this has forced me to reach out to people who I really didn't know before. (\#21, 75 y/o Jewish female, widow lives alone in condo) 
Difficult to support others at times

Support mismatch

\footnotetext{
We have in our condominium a community, and I've stepped up. I was previously publishing just a single sheet with the [religious] times of services, and so on. I've extended that into a newsletter and I've found it to be quite a positive aspect of the pandemic. I would never have done it, had we not been shut in. So now I'm just on issue 21 of the newsletter which includes articles and recipes and, you know, lighter material... and people are very pleased about what I've done. (\#13, 73 y/o Jewish male, living with spouse in a condo)

I would just take a little chair, sit outside her window when they open up the top so we could hear each other talk you know, stuff like that. ... like not being able to go in and explain to her, that's been my biggest... breaks my heart! because she doesn't understand....and then she'll say like there's nobody here, nobody comes, and stuff like that, 'cause they're all confined to their rooms so they don't leave the room at all... and she hasn't left it in three or four months so that's hard (\#4,69 y/o Caucasian female, lives with immune compromised spouse in a house) I would say that my younger son is much more worried about the fact that I'm an older woman who lives alone. He has much more germaphobe and much more worried about these things... My son is horrified, but I go at 7am to get my groceries... I don't tell him everything that I know will upset him. (\#21, 75 y/o Jewish female, widow lives alone in condo)

The way my children, and even grandchildren, keep saying 'bubby don't, don't do this, don't do that'... because it's not me.... my daughter did the majority of our shopping. But I really don't like it. (\#14, 70 y/o Irish Jewish female, lives with spouse in condo).
} 


\section{References}

1. Centers for Disease Control and Prevention. (2021). Risk for COVID-19 infection, hospitalization, and death by age group. Published February 18, 2021. Accessed April 3, 2021. https://www.cdc.gov/coronavirus/2019-ncov/covid-data/investigationsdiscovery/hospitalization-death-by-age.html

2. Li, Y., Ashcroft, T., Chung, A., Dighero, I., Dozier, M., Horne, M., Emiie, McSwiggan. E, Shamsuddin, A., Nair, H.; for the Usher Network for COVID-19 (2021). Risk factors for poor outcomes in hospitalised COVID-19 patients: A systematic review and meta-analysis. Journal of Global Health, 11:10001.

3. Yanez, N.D., Weiss, N.S., Romand, J.A. \& Treggiari, M.M. (2020). COVID-19 mortality risk for older men and women. BMC Public Health 20, 1742. https://doi.org/10.1186/s12889-020-09826-8

4. Ward, M., McGarrigle, C., Hever, A., O'Mahoney, Moynihan, S., Loughran, G., Kenny, R.A. (2020). Loneliness and social isolation in the COVID-19 Pandemic among the over 70s: Data from The Irish Longitudinal Study on Ageing (TILDA) and ALONE. Trinity College Dublin: The Irish Longitudinal Study on Ageing. Available from: https://tilda.tcd.ie/publications/reports/Covid19SocialIsolation/

5. Douglas, H., Georgiou, A., \& Westbrook, J. (2017). Social participation as an indicator of successful aging: An overview of concepts and their associations with health. Australian Health Review, 41(4), 455-462. doi:10.1071/AH16038

6. Golden, J., Conroy, R. M., Bruce, I., Denihan, A., Greene, E., Kirby, M., \& Lawlor, B. A. (2009). Loneliness, social support networks, mood and wellbeing in community-dwelling elderly. International Journal of Geriatric Psychiatry, 24, 694-700. doi:10.1002/gps.2181

7. Sirven N, \& Debrand T. (2008). Social participation and healthy ageing: An international comparison using SHARE data. Social Science E Medicine, 67(12):2017-2026. doi:10.1016/j.socscimed.2008.09.056

8. Carstensen, L.L., Shavit, Y.Z., Barnes, J.T. (2020). Age advantages in emotional experience persist even under threat from the COVID-19 pandemic. Psychological Science, 31(11), 1374-1385. doi:10.1177/0956797620967261

9. González-Sanguino, C., Ausín, B., Castellanos, M. Á., Saiz, J., López-Gómez, A., Ugidos, C., \& Muñoz, M. (2020). Mental health consequences during the initial stage of the 2020 coronavirus pandemic (COVID-19) in spain. Brain, Behavior, and Immunity, 87, 172-176. https://doi.org/10.1016/j.bbi.2020.05.040

10. Van Tilburg, T. G., Steinmetz, S., Stolte, E., van der Roest, H., \& de Vries, D. H. (2020). Loneliness and mental health during the COVID-19 pandemic: A study among dutch older adults. The Journals of Gerontology. Series B, Psychological Sciences and Social Sciences, https://doi.org/10.1093/geronb/gbaa111

11. Czeisler, M., Lane, R., Petrosky, E., Wiley, J., Christensen, A., Njai, R., Weaver, M.D., Robbins, R., Facer-Childs, E.R., Barger, L.K., Czeisler. C.A., Howard, M.E., \& Rajaratnam, S.M.W. (2020). Mental Health, Substance Use, and Suicidal Ideation During the COVID-19 Pandemic. MMWR. Morbidity And Mortality Weekly Report, 69(32), 1049-1057. doi: 10.15585/mmwr.mm6932a1

12. Dionne, M., Roberge, M-C., Brousseau-Paradis, C., Dube, E., Hamel, D., Rochette, L., Tessier, M. (2020). COVID-19 - Pandémie, bien-être émotionnel et santé mentale. Institut national de santé publique du Québec. Publication no: 3083. https://www.inspq.qc.ca/covid-19/sondages-attitudes-comportements-quebecois/sante-mentale-decembre-2020

13. Losada-Baltar, A., Jiménez-Gonzalo, L., Gallego-Alberto, L., Pedroso-Chaparro, M., Fernandes-Pires, J., \& MárquezGonzález, M. (2021). "We are staying at home." Association of self-perceptions of aging, personal and family resources, and loneliness with psychological distress during the lock-down period of COVID-19. Journals of Gerontology. Series B, Psychological Sciences and Social Sciences, 76(2), e10-e16. https://doi.org/10.1093/geronb/gbaa048

14. Lazarus, R. S., \& Folkman, S. (1984). Stress, appraisal, and coping. Springer publishing company.

15. Kroenke, K., Spitzer, R. L., \& Williams, J. B. W. (2001). The PHQ-9: Validity of a brief depression severity measure. Journal of General Internal Medicine, 16(9), 606-613. https://doi.org/10.1046/j.1525-1497.2001.016009606.x

16. Braun, V., \& Clarke, V. (2012). Thematic Analysis. In Cooper, H. (Ed.), APA Handbook of Research Methods in Psychology: Vol. 2. Research Designs (57-71). American Psychological Association. 
17. Losada-Baltar, A., Jiménez-Gonzalo, L., Gallego-Alberto, L., Pedroso-Chaparro, M., Fernandes-Pires, J., \& MárquezGonzález, M. (2021). "We are staying at home." Association of self-perceptions of aging, personal and family resources, and loneliness with psychological distress during the lock-down period of COVID-19. Journals of Gerontology. Series B, Psychological Sciences and Social Sciences, 76(2), e10-e16.

18. Stainback, K. Hearne, B.N., Trieu, M.M (2020). COVID-19 and the 24.7 news cycle: Does COVID-19 new exposure affect mental health? Socius: Sociological Research for a Dynamic Work, 6, 1-15. doi: 10.1177/2378023120969339

19. Sparrow, E.P., Swirsky, L.T., Kudus, F., Spaniol, J. (2021). Aging and altruism: A meta-analysis. Psychology and Aging, 36(1), 49-56. http://dx.doi.org/10.1037/pag0000447

20. Kahana, E., Bhatta, T., Lovegreen, L.D. (2013). Altruism, helping, and volunteering: Pathways to well-being in late life. Journal of Aging Health, 25(1), 159-187 . https://doi-org.ezproxy.lib.ryerson.ca/10.1177/0898264312469665

21. Long, C.R. and Averill, J.R. (2003), Solitude: An Exploration of Benefits of Being Alone. Journal for the Theory of Social Behaviour, 33, 21-44. https://doi.org/10.1111/1468-5914.00204

22. Kim, E.S., Shiba, K., Kubzansky, L.D. (2020). Sense of purpose in life and five health behaviors in older adults. Preventive Medicine, 139, 106172. https://doi.org/10.1016/j.ypmed.2020.106172

23. Irving, J., Davis, S., \& Collier, A. (2017). Aging With Purpose: Systematic Search and Review of Literature Pertaining to Older Adults and Purpose. The International Journal of Aging and Human Development, 85(4), 403-437. https://doi.org/10.1177/0091415017702908

24. Afifi, T.D., Basinger, E.D., Kam, J.A. (2020). The extended theoretical model of communal coping: Understanding the properties and functionality of communal coping. Journal of Communication 70, 424-446.

25. Meisner, B. A., Dogra, S., Logan, A.J., Baker, J., Weir, P. L. (2010). Do or decline?: comparing the effects of physical inactivity on biopsychosocial components of successful aging. J Health Psychol, 15(5). 688-96. doi: 10.1177/1359105310368184. PMID: 20603292

26. Winterbotham, S. \& du Preez, J. (2016). Psychosocial wellbeing in active older adults: A systematic review of qualitative literature. International Review of Sport and Exercise Psychology, 9(1) 96-115. doi: 10.1080/1750984X.2015.1122075

27. Ryan, R.M., \& Deci, E.L. (2000). Self-determination theory and the facilitation of intrinsic motivation, social development, and well-being. American Psychologist, 55(1),68-78.

28. Fredrickson, B. L. (2004). Gratitude, like other positive emotions, broadens and builds. In R. A. Emmons \& M. E. McCullough (Eds.), The Psychology of Gratitude (pp. 145-166). New York, NY: Oxford University Press.

29. Hong, J., Lachman, M., Wilson, C. L., Nakamura, J. S., \& Kim, E. S. (2021). The positive influence of sense of control on physical, behavioral, and psychosocial health in older adults: An outcome-wide approach. Preventive Medicine. https://doi.org/10.1016/j.ypmed.2021.106612

30. Heo, J., Chun, S., Lee, S., Lee, K.H., \& Kim, J. (2015). Internet Use and Well-Being in Older Adults. Cyberpsychology, Behavior, and Social Networking, 18(5), 268-272. http://doi.org/10.1089/cyber.2014.0549

31. Levy, B. R., Ferrucci, L., Zonderman, A. B., Slade, M. D., Troncoso, J., \& Resnick, S. M. (2016). A culture-brain link: Negative age stereotypes predict Alzheimer's disease biomarkers. Psychology \& Aging, 31(1), 82-88. doi: 10.1037/pag0000062

32. Meisner, B. A., \& Levy, B. R. (2016). Age stereotypes' influence on health: Stereotype Embodiment Theory. In V. Bengtson \& R. Settersten (Eds.), Handbook of Theories of Aging (3rd ed., Chap. 14, pp. 259-276). New York, NY: Springer Publishing Company

33. Raphael, D. (2011). A discourse analysis of the social determinants of health. Critical Public Health, 21(2), 221-236. 